\title{
1 Thermal healing of realistic flaws in glass
}

2 Marco Zaccaria $^{1}$ and Mauro Overend ${ }^{2}$

$3 \quad{ }^{1} \mathrm{BE}, \mathrm{MSc}$, Department of Engineering, University of Cambridge, UK, corresponding

$4 \quad$ author, email mz287@cam.ac.uk

$5 \quad$ 2BE\&A, MSc, PhD, CEng MIStructE MICE, Senior Lecturer in Building Engineering Design,

$6 \quad$ University of Cambridge, UK, email: mo318@cam.ac.uk

\section{Abstract}

8 For any given environmental conditions the tensile strength of glass is a function of the

9 geometry of the critical flaw and the residual stresses in the vicinity of the flaw. The strength of heat treated glass is conventionally considered to be equal to the sum total of the residual stress and the extrinsic strength of annealed glass. Recent experiments suggest that there is an additional contribution to strength due to crack healing. In order to quantify it, uniaxial and equibiaxial strength tests on both as-received and carefully annealed glass specimens were performed for different edge geometries and edge finishes. The results show that strength recovery due to healing is significant and this strength gain appears to correlate with the quality of the edge finish. Possible explanations of this phenomenon are provided. Independently of healing effects, it was also found that the edge quality has a marginal effect on the mean strength, but has a significant positive effect at low fractile values often used in design applications. 
Introduction

27 Over the past century glass has been used in increasing volumes in buildings. Its role has diversified: from simply supported panels for windows, to glass façades with ever increasing sizes of glass panels and smaller supported areas. The trend of using glass in a more structural manner extends to other applications such as staircases and roofs. Post-production processes such as tempering and lamination have brought about significant improvements in the performance of glass. However, the fundamental reasons for some of the strength and failure phenomena in glass are not fully understood.

Theoretically glass is a very strong material, with an intrinsic (i.e. flawless) tensile strength based on intermolecular forces as high as 32 GPa (Shelby 1997), but this is significantly reduced by stress concentrations at the tip of surface flaws. These flaws, also known as Griffith flaws, are unavoidable consequences of handling, transportation or in-service weathering and are generally found in large numbers on the surface of glass and can be classified as scratches or digs (Fig. 1). When the flaws are subjected to crack opening stresses (aka mode I loading), the stress concentration at the crack tip is described by the stress intensity factor $K_{I}$, which is a function of the shape and depth of the flaw. Irwin (1957) defined mode I loading as:

$K_{I}=Y \sigma \sqrt{\pi a}$

45 where,

$46 \quad Y$ is the geometry factor accounting for the shape of the crack,

$47 \sigma$ is the tensile stress normal to the crack, $a$ is the crack depth. 
It is particularly difficult to measure the flaw geometry and size prior to fracture. In fact, the flaw tip tends to be too small or between surfaces in close optical contact that is impossible to identify it from a top view with an optical microscope. Other instruments such as surface profilometers are equally unsuitable as they are unable to penetrate to the depth of the flaw tip. This difficulty is compounded further by the presence of median and lateral cracks (Fig. 2) that extend from the tip of the surface flaw. These cracks are formed when the glass is chipped or scratched, even when this is done by carefully controlled indentation or cutting (Schula and Schneider, 2013).

A common way of increasing extrinsic tensile strength of glass is tempering (thermal or chemical). These processes induce a residual stress state of compression in the surfaces regions of the glass and tension in the core of the glass. The compression on the surface enables the glass to resist tensile stresses at least as high as the residual stress, providing that there are no flaws deeper than the pre-compression layer. The processes of thermal and chemical tempering are not described here for brevity, but can be found in more specific literature (Haldimann et al. 2008, Zijlstra and Burggraaf 1968). Commercially annealed glass is not entirely stress-free, in fact a small degree of residual stress, ranging from 4-11 MPa, has also been reported on as-received (commercially annealed) soda-lime-silica glass from float plants. This residual stress in commercially annealed glass is attributed to the cooling step in the annealing lehr of the float process which is not sufficiently slow to prevent residual stress from forming altogether (Zaccaria and Overend 2012). In this paper the term "annealed glass" is used to describe soda-lime-silica glass that is free of residual stress. The laboratory process performed to achieve this is described in subsequent parts of this paper. 
Recently it was observed (Nielsen et al. 2010) that the extrinsic strength $\left(f_{F T}\right)$ of fully tempered glass (FTG) is not simply the sum total of the extrinsic strength of annealed glass $\left(f_{A N}\right)$ and the surface residual stress $\left(\sigma_{R E S}\right)$ :

$f_{F T} \neq f_{A N}-\sigma_{R E S}$

But an additional strength is also recorded, leading to:

$f_{F T}=f_{A N}-\sigma_{R E S}+f_{H E A L}$

where $f_{H E A L}$ is a strength gain due to crack healing.

A similar additional strength has been recorded (Zaccaria and Overend 2014) for chemically tempered glass (CTG) suggesting that equation (3) could be extended to all glasses that are subjected to a temperature profile of the type used in post-production processes. Equation (3) indicates that the extrinsic strength is governed by the critical flaw, residual stress and healing and is usually obtained from destructive tests, but the contribution from healing is not fully characterised.

Crack healing can be defined as a spontaneous process consisting of crack closure associated with a strength recovery. Griffith (1920) postulated that cracking could be a reversible process only in the case of very narrow cracks, i.e. when the two cracked surfaces correspond to one another and there is no debris between them.

Several researchers have studied the underlying causes of crack healing. The main parameters investigated are humidity and temperature profile. Healing was measured in terms of the energy required to re-open an artificial crack and in some studies was also observed visually.

Crack healing was investigated in humid and inert conditions, noticing that humidity prevents re-bonding by triggering chemical reactions at the flaw tip (Wiederhorn and Townsend 1970). Michalske and Fuller (1985) focused on the effect of controlled levels of humidity ranging from $0.01 \%$ to $100 \%$ and they also proposed a chemical model of 
crack healing. The effect of temperature on crack healing was studied by Hrma et al. (1988), who investigated various temperature profiles and concluded that temperature favours healing, but that prolonged heat treatments lead to weakening. In a study by Inagaki et al. (1985) healing was observed visually on notched glass samples under cyclic loading and crack closure was ascribed to a mechanism similar to hysteresis. Crack closure was also visually observed by Girard et al. (2011), who took humidity and heat treatment into account and described healing as a step-by-step process involving relaxation of the stress immediately below the crack tip caused by indentation, crack blunting, followed by crack closure.

The existing body of research identifies the main factors that appear to affect crack healing in glass. All of the studies were performed by creating an artificial crack in glass and subsequently measuring the energy required to re-open it. These studies provide very useful information, but the phenomenon merits further investigation, in particular, to quantify:

1- The extent to which realistic (rather than indented) flaws are affected by crack healing. Realistic (Griffith) flaws would be expected to be more susceptible to healing, due to their size and optical contact, but this has yet to be ascertained;

2- The true strength gain resulting from thermal crack healing. In fact, any thermal treatment typically produces not only a residual stress $\left(\sigma_{R E S}\right)$, which enhances its performance, but also an additional strength due to healing $\left(f_{H E A L}\right)$;

3- The effect of thermal crack healing on a realistic flaw population rather than on a single flaw, and the strength increase at lower fractile values (rather than simply on the mean strength) as these values are important in real-world applications.

The aim of this paper is to quantify the strength gain of glass due to crack healing $\left(f_{H E A L}\right)$ as a result of temperatures encountered during an annealing cycle. In doing so it 
addresses the three principal gaps in knowledge listed above. This is done by carefully annealing as-received soda-lime-silica float glass. Annealing has the benefit of removing any remaining residual stress in the glass while providing a heating cycle below its transition temperature, thereby leaving the atomic structure unaffected. The annealed glass is subsequently tested to destruction and these results are compared to strength data obtained from as-received glass. To account for different realistic flaw populations, one type of untreated glass surface and three types of industry standard edge finish are tested on a coaxial double ring (CDR) and a 4-point bending (4PB) set-up, respectively. The strength contribution of residual stress $\left(\sigma_{R E S}\right)$ is determined by photoelastic measurements with a scattered light polariscope (SCALP) (Anton and Aben 2003).

\section{Method}

Standard soda-lime-silica glass (SLSG) has been used in this study. Its expected chemical composition and properties are shown in table 1 and table 2, respectively.

Four series were investigated (Table 3), each consisting of:

- 16 as-received float glass;

- 16 as-received float glass subsequently annealed in the laboratory.

The series were tested as follows:

- Series I coaxial double ring (CDR), size of the specimens 150 × 150 x 6mm;

- Series II, III, IV four point bending (4PB), size of the specimens $150 \times 20 \times 6 \mathrm{~mm}$.

The three series tested in 4PB differ from one another in terms of edge finish: as cut, chamfered grinded, chamfered polished (Figure 3).

Surface pre-compression was measured with a calibrated scattered light polariscope (SCALP 5.0). 
Specimen edges were investigated before and after annealing by means of an optical microscope to identify any changes in flaw morphology.

\section{Coaxial double ring tests}

A CDR setup was used to test the surface strength of as-received and annealed glass (Fig. 3). The glass specimens were tested using a universal testing machine with a $30 \mathrm{kN}$ load cell. The diameters of the loading and support rings were $51 \mathrm{~mm}$ and $126 \mathrm{~mm}$, respectively. A double hinged connection was placed between the cross-head and the loading ring to ensure uniform contact between the loading ring and the glass. Before testing, a UV-light detector was used to identify the tin side and all CDR specimens were tested with the tin side in tension. A self-adhesive film was applied to the compression side (air side) in order to hold the glass fragments together after fracture. The specimens, jig sizes and the cross head speed comply with ASTM C 1499 (2003). The crosshead speed of $0.02 \mathrm{~mm} / \mathrm{s}$ was selected in order to fracture the specimens within 2 minutes, thereby limiting the effect of slow crack growth (Wiederhorn 1967 and Munz and Fett 1999). The CDR setup induces an equibiaxial stress state on the surface of the glass within the loading ring, therefore fracture is expected to originate at the largest flaw within the loading ring, where the tensile stress is at its peak. Load at failure and test duration were recorded.

\section{Four point bending}

A four point bending setup was used to test the strength of three different edge finishes of as-received and annealed glass. The edge finish was as follows (Fig. 4):

- As-cut: the edge is sharp and might not be perfectly straight; density of flaws is not controlled (DIN 1986); 
- Grinded: the edge is chamfered and grinded; chips and flaws are allowed; the finish is opaque (DIN 1986);

- Polished edge: the edge is chamfered and polished; flaws and chips do not occur; slight polishing marks are allowed; the surface finish is shiny (DIN 1986).

All chamfers are $1.5 \mathrm{~mm}$ long at an angle of $45^{\circ}$. The different edge finish affects the morphology and the density of the flaws, which will directly affect the stress at failure. However, the effect of the flaws cannot be quantified non-destructively, but can be determined by comparing the stress at failure.

The universal testing machine used is the same as for the CDR tests, fitted with a $4 \mathrm{~PB}$ jig that loads the $150 \mathrm{~mm}$ long glass specimens at third points (i.e. $50 \mathrm{~mm}$ sheer span and $50 \mathrm{~mm}$ load span). A double hinged connection between the crosshead and the loading arm allows the load to be applied uniformly. The sizes of the specimens and the jigs comply with ASTM C 1161 (2008). A crosshead speed of $0.02 \mathrm{~mm} / \mathrm{s}$ was used in these tests, to induce fracture within 2 minutes.

The 4PB setup induces bending about the major axis of the specimens, thereby resulting in a uniaxial tensile stress state which is constant along the $50 \mathrm{~mm}$ load span length of both sides of the beam in order to retain glass fragments together after fracture.

Annealing and surface microscopy

Annealing was performed in the laboratory to remove the residual stress from the asreceived glass. The annealing cycle was identical to that used by El-Sayed and Hand (2011) i.e. heating the glass at a rate of $2^{\circ} \mathrm{C} / \mathrm{min}$ up to $560^{\circ} \mathrm{C}$, holding for 2 hours and then cooling it at $2^{\circ} \mathrm{C} / \mathrm{min}$ to room temperature. 
Edges of series II, III and IV were also examined with an optical microscope before and after the annealing process (Fig. 5). Flaws were recorded and measured. The investigation was carried out to establish whether the annealing process had caused any visible morphological changes in the flaws.

\section{Photoelastic stress measurements}

Residual stresses were measured for all the specimens with a SCALP. One reading per side per specimen was performed. For the series I the reading was made in the middle of the plate where failure was expected to originate. For the remaining series II, III, IV, although failure was expected to originate at the edges, it was not possible to measure the residual stress at this location due to restrictions of the device (Glasstress Ltd, Scattered Light Polariscope SCALP instruction manual ver 5.5, unpublished). A measurement representative of the residual stress of the specimen was therefore made on the $20 \mathrm{~mm}$ side, parallel to the length of the specimen (Fig. 5). Typical SCALP measurements are shown in Fig. 7 and 8 for as-received and annealed specimens, respectively. The arithmetic mean of the residual stresses obtained for the respective series are shown in table 5. Edge working in the form of cutting, grinding and polishing is also expected to produce residual stresses in the vicinity of the edge, but it was not possible to measure this and these residual stresses are assumed to be relatively constant within each series thereby having a negligible effect on the comparisons made in this paper.

\section{Results}

Stress at failure was calculated using Kirchhoff-Love plate theory for CDR tests and Euler-Bernoulli beam theory for the 4PB tests. 
222 For CDR tests, in the particular case of annular loading and support stress at failure

223 equals (ASTM C 1499-2003 and Young et al. 2002):

224

$\sigma_{f}=\frac{3 L}{2 \pi h^{2}}\left[(1-v) \frac{\emptyset_{S}^{2}-\emptyset_{L}^{2}}{2 \emptyset^{2}}+(1+v) \ln \frac{\emptyset_{S}}{\emptyset_{L}}\right]$

225 where,

$226 L$ is the load at failure in $\mathrm{N}$,

$227 h$ is the glass thickness in $\mathrm{mm}$,

$228 \emptyset_{S}$ is the diameter of the reaction ring in $\mathrm{mm}$,

$229 \emptyset_{L}$ is the diameter of the loading ring in $\mathrm{mm}$,

$230 v$ is the Poisson ratio

$231 \varnothing$ is the diameter of a circle that expresses the characteristic size of the plate and for a

232 squared plate can be expressed as follows:

233

$\emptyset=\frac{l}{0.90961+0.12652 \frac{h}{\phi_{S}}+0.00168 \ln \frac{l-\emptyset_{S}}{h}}$

234 where $l$ is the length of the side of the square glass specimen in $\mathrm{mm}$.

235 For the 4PB tests, the reduction in second moment of area due to the chamfers was

236 taken into account, as failing to do so would lead to an error of $11.6 \%$ in tensile stress.

237 The relatively simple equations are not shown here for brevity.

238 In order to compare data independent of stress history, failure stresses were converted

239 to a 60 s equivalent stress (Haldimann et al. 2008 and Overend and Zammit 2012). This

240 represents the constant tensile stress to which the given specimen should be subjected

241 in order to induce failure after 60 seconds. In the general case this can be expressed as

242 follows:

$\left.243 \quad \sigma_{t 60}=\left[\frac{1}{t_{0}} \int_{0}^{t_{f}} \sigma^{n}(t) d t\right)\right]^{1 / n}$

244 where, 
$\sigma_{t 60}$ is the $60 \mathrm{~s}$ equivalent stress,

246 to is the equivalent time period, (60s),

$247 \sigma(t)$ is the stress history,

$248 t_{f}$ is the time at failure of the test,

$249 n$ is the slow crack growth parameter, 16 for float soda-lime-silica glass (Haldimann et

250 al. 2008).

251 For the case of constant stress rate used in this study, Eq. (5) can be re-written as

252 follows:

$253 \quad \sigma_{t 60}=\sigma_{f}\left[\frac{t_{f}}{t_{60}(n+1)}\right]^{1 / n}$

254 Mean 60 s equivalent failure stresses are shown in table 4.

255 Two-parameter Weibull statistical analysis was performed on the $60 \mathrm{~s}$ equivalent

256 failure stresses. The method of moments (EN 12603-2002) was used to find the best

257 fitting 2-parameter Weibull curve to the given test data. Table 6 shows: the resulting

258 Weibull parameters $\theta$ and $\beta$, representing the scale parameter and the shape

259 parameter, respectively; the Anderson-Darling goodness-of-fit statistic $\rho_{A D}$; and the

$260 \quad 0.001$ and 0.5 fractile strengths, $f_{f ; 0.001}$ and $f_{f ; 0.5}$, respectively. The corresponding

261 cumulative Weibull plots are shown in Figs. 9-12.

262 The mean strength increase due to healing, $\bar{f}_{\text {Heal }}$ for each series can be determined by

263 re-arranging Eq. (3) and accounting for any residual stress that is present after the

264 laboratory annealing $\left(\sigma_{R e s A N}\right)$, giving:

$265 \bar{f}_{\text {Heal }}=\frac{1}{16} \sum_{i=1}^{16}\left[\left(f_{A N, t 60}+\sigma_{R e s A N}\right)-\left(f_{A R, t 60}+\sigma_{R e s A R}\right)\right]_{i}$

266 where,

$267 f_{A N, t 60}$ is the $60 \mathrm{~s}$ equivalent strength of the i-th annealed glass specimen,

$268 \sigma_{\text {ResAN }}$ is the surface residual stress of the $\mathrm{i}$-th annealed specimen, 
$269 f_{A R, t 60}$ is the $60 \mathrm{~s}$ equivalent strength of the i-th as-received glass specimen,

$270 \sigma_{\text {ResAR }}$ is the surface residual stress of the $\mathrm{i}$-th as-received specimen,

$271 \quad 16$ is the number of specimens for each batch.

272 The expressions in the first and second parenthesis of Eq. (7) are a measure of the

273 extrinsic strengths of annealed and as-received glass, respectively. The difference

274 between the extrinsic strengths of annealed and as-received glass is a measure of the

275 strength gain due to healing. Equation (7) is in fact equivalent to:

$276 f_{\text {Heal }, P x}=\left[\left(f_{A N, P x}+\bar{\sigma}_{\text {ResAN }}\right)-\left(f_{A R, P X}+\bar{\sigma}_{\text {ResAR }}\right)\right]$

277 where, for each series,

$278 f_{\text {Heal,Px }}$ is the strength gain corresponding to the chosen fractile $P x$;

$279 f_{A N, P x}$ is the annealed glass strength corresponding to the chosen fractile $P x$;

$280 f_{A R, P x}$ is the as-received glass strength corresponding to the chosen fractile $P X$.

281 In this paper Eq. (8) has been used to calculate the extrinsic strength gain due to healing

282 in each series at the 0.5 and 0.001 fractiles (table 7).

283 Comparison of flaws performed with an optical microscope before and after annealing

284 did not reveal any morphological changes in the density of the flaw. Typical

285 micrographs from this study are shown in fig. 6 a-d for as-cut and polished edge finish

286 (series II, IV). It was difficult to ascertain any differences in the depth of the flaws

287 perpendicular to the plane of view, but there was no apparent change to the length

288 along the plane of view and other visible morphological features.

290 Discussion

291 Thermal healing

292 The strength gain due to crack healing can be assessed by comparing the extrinsic

293 strength of annealed glass with the extrinsic strength of as-received glass for each test 
series. By considering mean values and 0.5 fractile (best-fit) values in table 7 it is evident that strength gain occurs for all series. There are however significant differences in the lower fractile (0.001) values. More specifically, the as-cut and the grinded series show an extrinsic strength loss, whilst the CDR and the polished series exhibit a gain in extrinsic strength. This suggests that healing can have a significant influence on the low fractile values typically used in real-world applications, but that this phenomenon is sensitive to the edge or surface quality. A further illustration of this can be seen in the Weibull plots in figs. 9-12, which show that heat treatment was successful in reducing the scatter of failure stress values (i.e. the gradient of the best-fit line) for smaller flaws (CDR and polished series) whilst it increased the scatter for consistent for all flaw sizes present on the polished edges.

The sensitivity of healing to edge/surface quality is confirmed further by considering the 4PB series alone. Here the strength gain appears to be correlated with the quality of the edge finish. More precisely, not only does the edge quality correlate with higher strength (as expected), but the extrinsic strength gain from thermal healing is also more significant. This trend is confirmed by the 0.001 fractile although in this case the improvement is from a significant strength loss for the as-cut series $(-28.8 \%)$ to a moderate strength loss $(-4.1 \%)$ to a substantial strength gain $(+35.0 \%)$.

In comparison, series I showed healing for all the fractiles, but the healing had a much larger beneficial effect on the lower fractile strength. This suggests that of all the flaw populations considered in this study, healing was most effective for the smaller flaws encountered on the glass surface (series I). 
Microscopical investigation of the edges before and after annealing did not show any change in flaw morphology (Fig. 6). However this does not rule out that a morphological change occurs at a smaller scale or on areas which are impossible to investigate with an optical microscope. A comparison of the flaw size and morphology before and after annealing would help to explain the nature of the healing mechanism. Currently it is possible to measure it only after failure (Fig. 13), but not before, thereby ruling out the possibility to know the flaw size before annealing. However, a possible explanation of the thermal healing mechanism can be drawn by merging the findings of this experimental investigation with the existing literature. In fact, it is likely that in the vicinity of the flaw tip a combination of applied stress, morphology of the flaw and humidity affect the strength before and after heat treatment. Namely, in as-received float glass (before heat treatment) (Fig. 14a):

- A residual stress profile with compression on the surface and tension in the core exists. This is typical of as-received float glass;

- There is humidity at the flaw tip.

- The crack is formed and its geometry is characterised by a sharp tip;

- This is immediately followed by the formation of radial/median/lateral cracks just below the flaw tip (Schula and Schneider 2013);

- Crack formation also causes local stresses at the flaw tip, similarly to those generated during an indentation (Anunmana et al. 2009);

After heat treatment (annealing) (Fig. 14b):

- The residual stress profile is relaxed as confirmed by the photoelastic stress measurements performed in this study; 
- The crack retains its overall morphology as confirmed by the visual inspection (Fig. 6), but an optically invisible blunting at the crack tip may occur. This increases glass strength by reducing stress concentrations (Watson et al. 2013);

- And/or sub-critical cracks tend to close (re-bonding) as they match the definition of reversible cracks (Griffith 1920);

- Local stresses in the vicinity of the flaw tip undergo relaxation (Girard 2011);

- If the crack surfaces are in close optical contact humidity levels at the tip would not rise instantaneously, thereby, leading to an apparent gain in strength (Wiederhorn and Townsend 1970,Michalske and Fuller 1985), but on its own it cannot explain the increase in strength observed in this study.

\section{Edge strength}

Another important finding independent of thermal healing, is that the quality of surface/edges (i.e. flaw density and morphology) investigated in this study (which are typical of those found in real-world applications) has a relatively small influence on the mean and 0.5 fractile strengths, but has a very significant effect at the low fractile strengths commonly used in design applications. For example, polished edges in the asreceived glass are on average 4.7 $\mathrm{MPa}(3.5 \%)$ stronger than as-cut edges (table 4), but the strength of polished edges at the 0.001 fractile value is $39.4 \mathrm{MPa}(114.2 \%)$ higher than that of as-cut edges (table 6).This influence of edge finish at low fractile values is even more pronounced after thermal treatment (annealing). The reason for this sensitivity at low fractile values is that although the mean (and 0.5 fractile) values are only marginally affected by edge finish, the scatter of failure strengths (and implicitly the flaw sizes) are significantly reduced by grinding and more so by polishing. This is also evident in the magnitude of the shape parameter $\beta$ in table 4 and manifests itself in 
the increasing slope in the best-fit lines when comparing across fig. 10, fig. 11 and fig. 12.

\section{Conclusions}

This study showed that thermal healing of realistic flaws can induce a significant strength gain in soda lime silica glass. This was quantified by testing as-received glass specimens and glass specimens carefully annealed in the laboratory and comparing their strength at failure. The effect on glass surface strength and on the edge strength of three different edge finishes was considered. The results showed that the mean strength increase for the glass surface, as-cut edges, and grinded edges was in the order of $1.9 \%$ to $4.8 \%$, but that this increase was $18.9 \%$ for polished edges. The effect of thermal healing at low fractile values used in design applications (e.g. 0.001) was even more pronounced for the polished edges with an increase as high as 35\%, whilst as-cut and grinded edges showed a decrease of $28.8 \%$ and $4.1 \%$, respectively. The overall trend was that a better quality edge finish resulted in a higher strength gain or healing. This study also showed that for the low strength fractiles commonly used in design applications, a good quality edge finish results in significantly higher edge strength. Namely as-received polished edges proved to be $114.2 \%$ stronger than as-received ascut specimens. The same figure for average values is as low as 3.5\% instead. The benefits of a good quality edge finish at low fractile values are even more substantial when glass undergoes thermal healing.

More work is required to better understand crack healing, in particular there is a need to: the transition temperature may trigger increased morphological modifications 
and changes at the atomic structure level. Also, thermal heating cycles typical of thermal tempering and chemical tempering could be of crucial importance for the application of these products; effect on different surface flaw populations.

400

401

\section{Acknowledgements}

402

The contribution of Chris Cavanagh to part of the experimental testing, Trend Marine

403 Ltd and EPSRCis gratefully acknowledged.

404

405

\section{Notation list}

406 The following symbols are used in this paper:

$407 \quad a=$ crack depth;

$408 f_{A N}=$ extrinsic strength of annealed glass;

$409 f_{A N, P x}=$ annealed glass strength for a given fractile $P_{x}$;

$410 f_{A N, t 60}=60 \mathrm{~s}$ equivalent strength of the $\mathrm{i}$-th annealed specimen;

$411 f_{A R, P x}=$ as-received glass strength for a given fractile $P_{x}$;

$412 f_{A R, t 60}=60 \mathrm{~s}$ equivalent strength of the i-th as-received specimen;

$413 f_{f ; 0.001}=0.001$ fractile strength;

$414 f_{f ; 0.5}=0.5$ fractile strength;

$415 f_{\mathrm{FT}}=$ extrinsic strength of fully tempered glass; 
$416 f_{H E A L}=$ strength gain due to healing;

$417 \bar{f}_{\text {Heal }}=$ average strength gain due to healing;

$418 f_{\text {Heal }, P x}=$ strength gain due to healing for a given fractile $P_{x}$;

$419 h=$ glass specimen thickness;

$420 \quad K_{I}=$ stress intensity factor for mode I loading;

$421 \quad L=$ load at failure;

$422 \quad l=$ length of the side of the square glass specimen;

$423 n$ = slow crack growth parameter;

$424 t_{0}=$ reference time period;

$425 \quad t_{f}=$ time to failure;

$426 \quad Y=$ flaw geometry factor;

$427 \beta=$ surface strength shape parameter describing Weibull distribution;

$428 \theta=$ surface strength scale parameter describing Weibull distribution;

$429 \quad v=$ Poisson's ration;

$430 \pi=3.14159265359 ;$

$431 \rho_{A D}=$ Anderson-Darling Weibull goodness of fit index;

$432 \sigma=$ nominal tensile stress normal to the crack plane;

$433 \sigma_{f}=$ stress at failure;

$434 \quad \sigma^{n}(t)=$ stress history;

$435 \sigma_{R E S}=$ surface residual stress;

$436 \sigma_{\operatorname{ResAN}}=$ surface residual stress of the i-th annealed glass specimen;

$437 \bar{\sigma}_{\text {ResAN }}=$ average surface residual stress of annealed glass;

$438 \sigma_{R e s A R}=$ surface residual stress of the i-th as-received glass specimen;

$439 \bar{\sigma}_{\text {ResAR }}=$ average surface residual stress of as-received glass;

$440 \quad \sigma_{t 60}=60$ s equivalent stress; 
$\emptyset=$ diameter of a circle that express the characteristic size of the glass plate;

$\emptyset_{L}=$ diameter of the loading ring;

$\emptyset_{S}=$ diameter of the reaction ring.

\section{References}

Anton, J., Aben, H. (2003). “A compact scattered light polariscope for residual stress measurement in glass plates." Proc. Glass processing days, Tampere, Finland. Anunmana, C., Anusavice, K. J., Mecholsky, J.J., (2009). “Residual stress in glass: indentation crack and fractography approaches." Dent.Mater., 40(11), 1453-1458. ASTM (2003).“Standard method for monotonic equibiaxial flexural strength of advanced ceramics at ambient temperature."C1499-03, West Conshohocken, PA. ASTM (2008)."Standard test method for flexural strength of advanced ceramics at ambient temperature."C1161-02c, West Conshohocken, PA. DIN (1986). "Glass in building; glass edges; concept, characteristics of edges types and finishes." 1249-11:1986-09, Berlin, Germany.

EN (2002). “Glass in building. Procedures for goodness of fit and confidence intervals for Weibull distributed glass strength data." 12603:2002, European committee for standardization, Brussels, Belgium.

EN (2004). “Glass in building - Basic soda lime silicate glass products - Part 1:

Definitions and general physical and mechanical properties". 572-1:2004, European committee for standardization, Brussels, Belgium.

El-Sayed, T., Hand, R. J. (2011). "Modelling the strengthening of glass using epoxy based coatings." J. Eur. Cer. Soc., 31, 2783-2791. soda-lime silicate glass." J. Am.Cer. Soc., 94, 2402-2407. 
466 Griffith, A. A. (1920). "The phenomena of rupture and flow in solids." Phil.Trans. R. Soc., 467 Series $A, 221,163-198$.

468 Haldimann, M., Luible, M., Overend, M. (2008).Structural use of glass.Struct. Eng.Doc. no. 469 10, International Association of Bridge and Structural Engineers.

470 Hrma, P., Han, W. T., Cooper, A. R. (1988). “Thermal healing of cracks in glass.”J. non471 cryst.solids, 102, 88-94.

472 Inagaki, M., Urashima, K., Toyomasu, S., Goto, Y., Sakai, M. (1985). “Work of fracture and 473 crack healing in glass." J. Am.Cer. Soc., 68, 704-706.

474 Irwin, G. (1957). "Analysis of stresses and strains near the end of a crack transversing a 475 plate."J. Appl. Mech., 24, 361-364.

476 Michalske, T. A., Fuller, E. R. (1985). “Closure and repropagation of healed cracks in 477 silicate glass.”J. Am.Cer. Soc., 68(11), 586-590.

478 Munz, D., Fett, T. (1999).Ceramics: mechanical properties, failure behaviour, materials 479 selection.Springer, Berlin and Heidelberg, Germany.

480 Nielsen, J. H., Olesen, J. F., Stang, H., (2010). “Characterization of the residual stress state 481 in commercially fully toughened glass". J. Mat. Civ. Eng., 22(2), 179-185.

482 Nielsen, J. H., Olesen, J. F., Poulsen, P. N., Stang, H. (2010). “Finite element 483 implementation of a glass tempering model in three dimensions."Comp. and Struct., 88, $484963-972$.

485 Overend, M., Zammit, K. (2012). “A computer algorithm for determining the tensile 486 strength of float glass" Eng. Struct., 45, 68-77.

487 Shelby, J. E., (1997). Introduction to glass science and technology. Roy. Soc. Chem. 488 Cambridge, UK. 
489

490

491

492

493

494

495

496

497

498

499

500

501

502

503

504

505

506

507

508

509

510

511

512

513

Schula, S., Schneider J. (2013).“Characterization of the scratch visibility of annealed and tempered soda-lime-silicate glass." Proc,. COST Action TU0905, Mid-term Conference on

Structural Glass, Porec, Croatia.

Sullivan, J. D., Lauzon, P. H. (1986). “Experimental probability estimators for Weibull plots."J.Mat. Sc., 5, 1245-1247.

Varshneya, A. K. (2012). Fundamentals of Inorganic Glasses, The society of Glass Technology, Sheffield, UK.

Watson, J., Nielsen, J. H., Overend, M. (2013). “A critical flaw size approach for predicting the strength of bolted glass connections".Eng.Struct.,57, 87-99.

Wiederhorn, S. M. (1967). "Influence of water vapour on crack propagation in soda-lime glass". J. Am.Cer. Soc., 50, 407-414.

Wiederhorn, S. M., Townsend, P. R. (1970). “Crack healing in glass.” J. Am.Cer. Soc., 68, 486-489.

Young, W., Budynas, R., Sadegh, A. (2002).Roark's formulas for stress and strain, $7^{\text {thed, }}$ McGraw-Hill, New York, NY.

Zaccaria, M., Overend, M. (2012). "Validation of a simple relationship between the fracture pattern and the fracture stress of glass."Proc., Engineered Transparency, Dusseldorf, Germany.

Zaccaria, M., Overend, M. (2014). “The mechanical performance of bi-treated glass."Proc.,Challenging Glass 4 \& COST Action TU0905 Final Conference, Lausanne, Switzerland.

Zijlstra, A. L., Burggraaf, A. J. (1968). "Fracture phenomena and strength properties of chemically and physically strengthened glass." J. Non-Cryst. Solids, 1, 49-68. 
515 Table 1. SLSG composition (\% mass) according to EN 572-1:2004.

516 Table 2. Relevant SLSG properties.

517 Table 3. Summary of test specimens.

518 Table 4. Test data and $60 \mathrm{~s}$ equivalent failure stresses.

519 Table 5. Measured residual stresses.

520 Table 6. Weibull analysis of 60 s equivalent failure stresses.

521 Table 7. Summary of extrinsic strengths and strength gains.

522

\section{$523 \quad$ Figure captions}

524 Fig. 1. Flaws on a glass pane surface, top view from an optical miscroscope.

525 Fig. 2. Vicker's indented glass beam cross-section after breakage.

526 Fig. 3. CDR test setup.

527 Fig. 4. From left to right as-cut, chamfered ground and chamfered polished edges.

528 Fig. 5. Schematic view of a 4PB specimen showing the edges examined under the

529 microscope and the position of the SCALP measurement.

530 Fig. 6. Micrograph of glass flaws: series II before (a) and after (b) annealing; series IV

531 before (c) and after (d) annealing.

532 Fig. 7. SCALP measurement on as-received glass.

533 Fig. 8. SCALP measurement on annealed glass.

534 Fig. 9. CumulativeWeibull plot for Series I.

535 Fig. 10. Cumulative Weibull plot for Series II.

536 Fig. 11. Cumulative Weibull plot for Series III.

537 Fig. 12. Cumulative Weibull for Series IV.

538 Fig. 13. Micrograph of polished edge after failure. 
539 Fig. 14. Schematic explanation of crack healing: (a) flaw, as-received float glass, (b) in540 lab annealed glass.

541 
Tables

543 Table 1. SLSG composition (\% mass) according to EN (2004).

\begin{tabular}{cccccc}
\hline $\mathbf{S i O}_{2}$ & $\mathbf{C a O}$ & $\mathrm{Na}_{2} \mathbf{O}$ & $\mathbf{M g O}$ & $\mathbf{A l}_{2} \mathbf{O}_{3}$ & Others \\
\hline $69-74 \%$ & $5-14 \%$ & $10-16 \%$ & $0-6 \%$ & $0-3 \%$ & $0-5 \%$
\end{tabular}

544

545 
Table 2. Relevant SLSG properties.

\begin{tabular}{lccl}
\hline Property & Symbol & Value & Source \\
\hline Density $\left(\mathrm{kg} / \mathrm{m}^{3}\right)$ & $\rho$ & 2500 & Haldimann et al. (2008) \\
Young's modulus (MPa) & $E$ & 70000 & Haldimann et al. (2008) \\
Poisson ratio (-) & $v$ & 0.23 & Haldimann et al. (2008) \\
Stress intensity factor $\left(\mathrm{MPa} \mathrm{m}^{1 / 2}\right)$ & $K_{I C}$ & 0.75 & Overend and Zammit (2012) \\
Slow crack growth parameter & $n$ & 16 & Overend and Zammit (2012) \\
Coefficient of thermal expansion $\left(10^{-6} \mathrm{~K}^{-1}\right)$ & $\alpha_{T}$ & 9 & Haldimann et al. (2008) \\
Glass transition temperature $\left({ }^{\circ} \mathrm{C}\right)$ & $T_{g}$ & 575 & Shelby (1997) \\
Annealing point $\left({ }^{\circ} \mathrm{C}\right)$ & $T_{a}$ & 550 & Shelby (1997) \\
Photoelastic constant $(\mathrm{TPa})$ & $C$ & 3.01 & Nielsen (2010) \\
\hline
\end{tabular}

547

548 
Table 3. Summary of test specimens.

\begin{tabular}{ccccc}
\hline Series & Dimensions (mm) & Edge Finish & Test & \# of specimens \\
\hline I & $150 \times 150 \times 6$ & N/A & CDR & $\begin{array}{c}16 \text { as-received } \\
16 \text { annealed }\end{array}$ \\
& & & & 16 as-received \\
II & $150 \times 20 \times 6$ & As-cut & $4 P B$ & 16 annealed \\
& & & & 16 as-received \\
III & $150 \times 20 \times 6$ & Grinded & $4 P B$ & 16 annealed \\
& & & & 16 as-received \\
IV & $150 \times 20 \times 6$ & Polished & $4 P B$ & 16 annealed \\
\hline
\end{tabular}

550

551 
552 Table 4. Test data and 60 s equivalent failure stresses.

\begin{tabular}{|c|c|c|c|c|c|c|}
\hline \multirow[t]{2}{*}{ Series } & \multicolumn{2}{|c|}{$\begin{array}{l}\text { Failure stress } \\
\qquad \text { (MPa) }\end{array}$} & \multicolumn{2}{|c|}{$\begin{array}{l}60 \text { s equivalent stress } \\
\text { (MPa) }\end{array}$} & \multicolumn{2}{|c|}{$\begin{array}{c}\text { Standard Deviation } \\
\text { (MPa) }\end{array}$} \\
\hline & $\begin{array}{c}\text { As- } \\
\text { received }\end{array}$ & Annealed & $\begin{array}{c}\text { As- } \\
\text { received }\end{array}$ & Annealed & $\begin{array}{c}\text { As- } \\
\text { received }\end{array}$ & Annealed \\
\hline I & 179.3 & 181.0 & 147.3 & 148.9 & 74 & 51 \\
\hline II & 173.1 & 172.6 & 134.5 & 135.2 & 28 & 38 \\
\hline III & 170.2 & 175.0 & 135.0 & 139.4 & 21 & 23 \\
\hline IV & 181.3 & 211.9 & 139.2 & 163.6 & 18 & 16 \\
\hline
\end{tabular}

553

554 
Table 5. Measured residual stresses.

\begin{tabular}{cccccc}
\hline Series & \multicolumn{2}{c}{$\begin{array}{c}\text { Mean Residual stresses } \\
\text { (MPa) }\end{array}$} & & \multicolumn{2}{c}{ Standard Deviation (MPa) } \\
\cline { 2 - 3 } \cline { 5 - 6 } I & -4.6 & -2.2 & & 0.37 & 0.71 \\
II & -4.2 & -2.4 & & 0.52 & 0.67 \\
III & -4.4 & -2.5 & & 0.53 & 0.59 \\
IV & -3.5 & -2.2 & & 0.61 & 0.56 \\
\hline
\end{tabular}

556

557 
Table 6. Weibull analysis of $60 \mathrm{~s}$ equivalent failure stresses.

\begin{tabular}{|c|c|c|c|c|c|c|}
\hline & \multirow[t]{2}{*}{ Series } & \multicolumn{2}{|c|}{$\begin{array}{c}\text { Weibull } \\
\text { Parameters }\end{array}$} & \multirow{2}{*}{$\begin{array}{c}\text { Goodness-of- } \\
\text { fit } \\
\rho_{A D}\end{array}$} & \multirow{2}{*}{$\begin{array}{c}\text { Fractile } \\
\text { strengths } \\
\boldsymbol{f}_{\boldsymbol{f} ; \mathbf{0 . 5}}\end{array}$} & \multirow{2}{*}{$\begin{array}{c}\text { Fractile } \\
\text { strengths } \\
\boldsymbol{f}_{\boldsymbol{f} ; \mathbf{0 . 0 0 1}}\end{array}$} \\
\hline & & $\boldsymbol{\theta}$ & $\beta$ & & & \\
\hline \multirow{2}{*}{ I } & As-received & 175.6 & 2.02 & 0.071 & 146.4 & 5.7 \\
\hline & Annealed & 167.0 & 3.27 & 0.11 & 149.7 & 20.3 \\
\hline \multirow{2}{*}{ II } & As-received & 148.9 & 4.72 & 0.11 & 137.8 & 34.5 \\
\hline & Annealed & 151.8 & 3.75 & 0.01 & 137.7 & 24.1 \\
\hline \multirow{2}{*}{ III } & As-received & 145.0 & 6.80 & 0.32 & 137.5 & 52.5 \\
\hline & Annealed & 151.3 & 6.08 & 0.29 & 142.5 & 48.6 \\
\hline \multirow{2}{*}{ IV } & As-received & 146.1 & 10.13 & 0.42 & 140.9 & 73.8 \\
\hline & Annealed & 170.6 & 12.25 & 0.55 & 165.6 & 97.1 \\
\hline
\end{tabular}

559 Note: values in italics indicate a poor Weibull fit. 
Table 7. Summary of extrinsic strengths and strength gains.

\begin{tabular}{|c|c|c|c|c|c|c|c|c|c|}
\hline \multirow[t]{2}{*}{ Series } & \multicolumn{3}{|c|}{$\begin{array}{c}\text { Extrinsic strength of } \\
\text { Annealed glass } \\
\text { (MPa) } \\
\boldsymbol{f}_{A N, P x}+\bar{\sigma}_{R e s A N}\end{array}$} & \multicolumn{3}{|c|}{$\begin{array}{c}\text { Extrinsic strength of } \\
\text { As-received glass } \\
\text { (MPa) } \\
f_{A R, P x}+\bar{\sigma}_{R e s A R}\end{array}$} & \multicolumn{3}{|c|}{$\begin{array}{c}\text { Extrinsic Strength gain } \\
\text { (MPa) }\end{array}$} \\
\hline & Mean & 0.5 & 0.001 & Mean & 0.5 & 0.001 & Mean & 0.5 & 0.001 \\
\hline I & 146.7 & 147.5 & 18.1 & 142.7 & 141.8 & 1.1 & $\begin{array}{c}4.0 \\
(2.8 \%)\end{array}$ & $\begin{array}{c}5.7 \\
(4.0 \%)\end{array}$ & $\begin{array}{c}17.0 \\
\text { (offlimits) }\end{array}$ \\
\hline II & 132.8 & 135.3 & 21.7 & 130.3 & 133.6 & 30.5 & $\begin{array}{c}2.5 \\
(1.9 \%)\end{array}$ & $\begin{array}{c}1.7 \\
(1.3 \%)\end{array}$ & $\begin{array}{c}-8.8 \\
(-28.8 \%)\end{array}$ \\
\hline III & 136.9 & 140.0 & 46.1 & 130.6 & 133.1 & 48.1 & $\begin{array}{c}6.3 \\
(4.8 \%)\end{array}$ & $\begin{array}{c}6.9 \\
(5.2 \%)\end{array}$ & $\begin{array}{c}-2.0 \\
(-4.1 \%)\end{array}$ \\
\hline IV & 161.4 & 163.4 & 94.9 & 135.7 & 137.4 & 70.3 & $\begin{array}{c}25.7 \\
(18.9 \%)\end{array}$ & $\begin{array}{c}26 \\
(18.9 \%)\end{array}$ & $\begin{array}{c}24.6 \\
(35.0 \%)\end{array}$ \\
\hline
\end{tabular}




\section{Scratches}

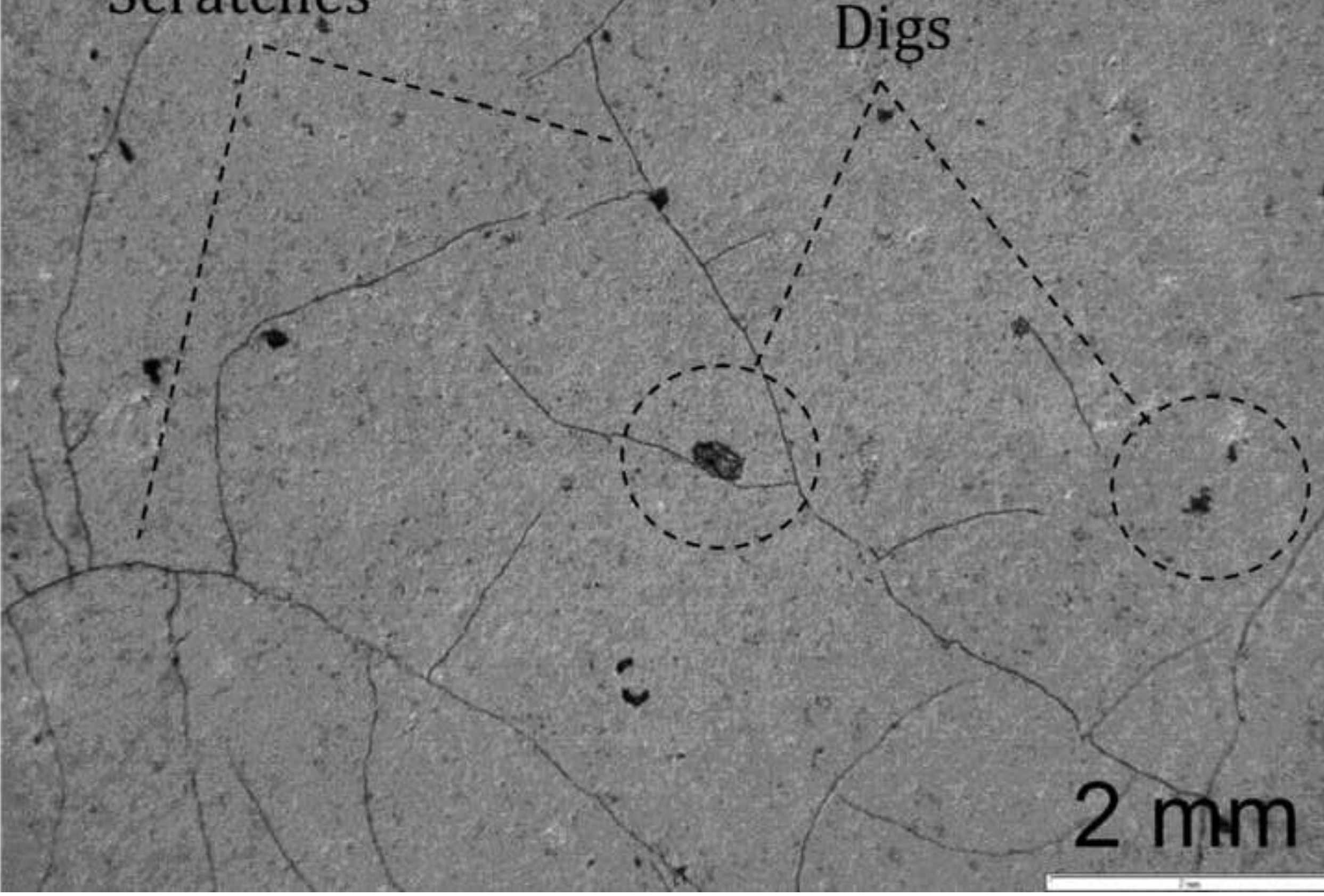




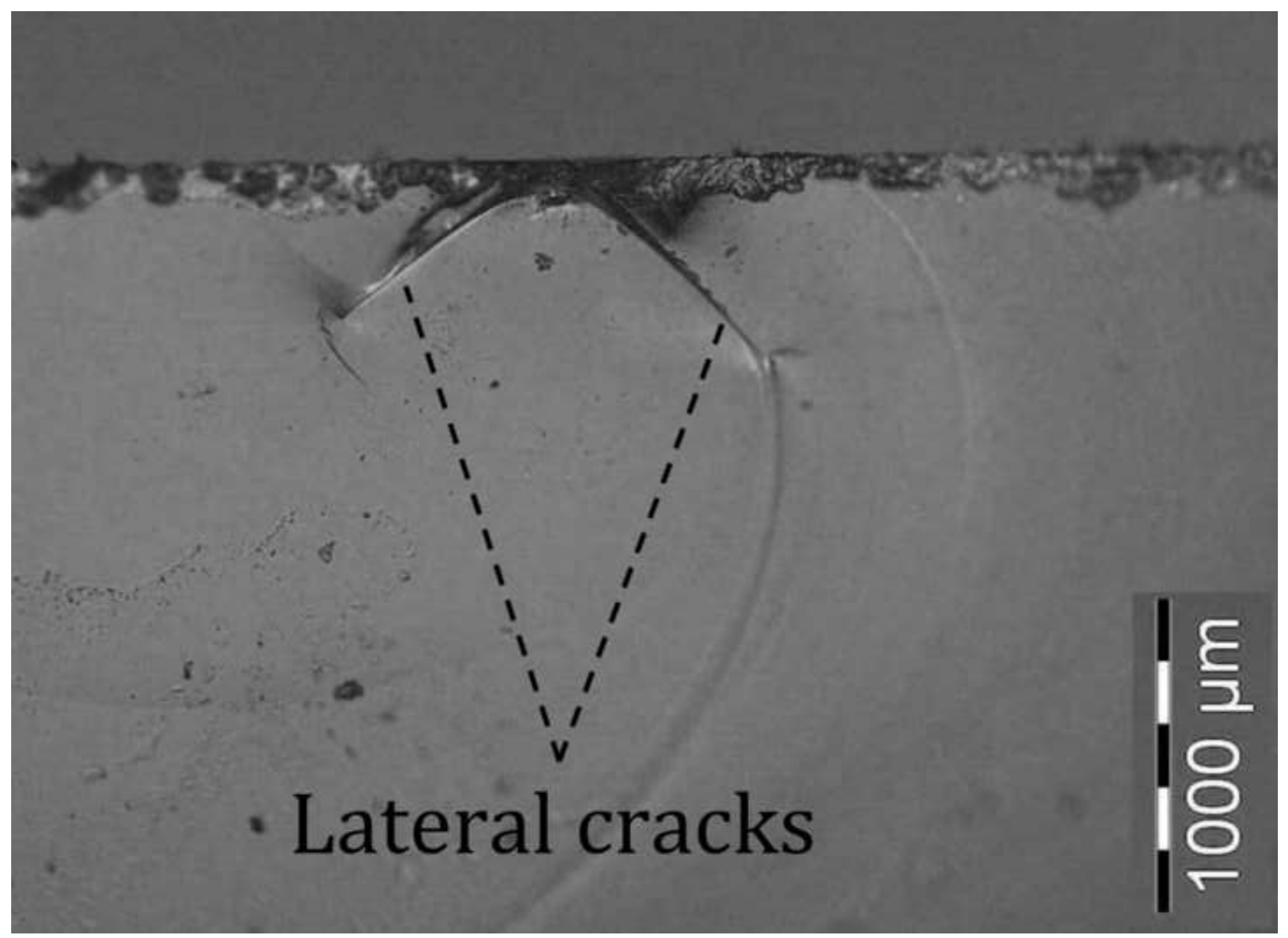




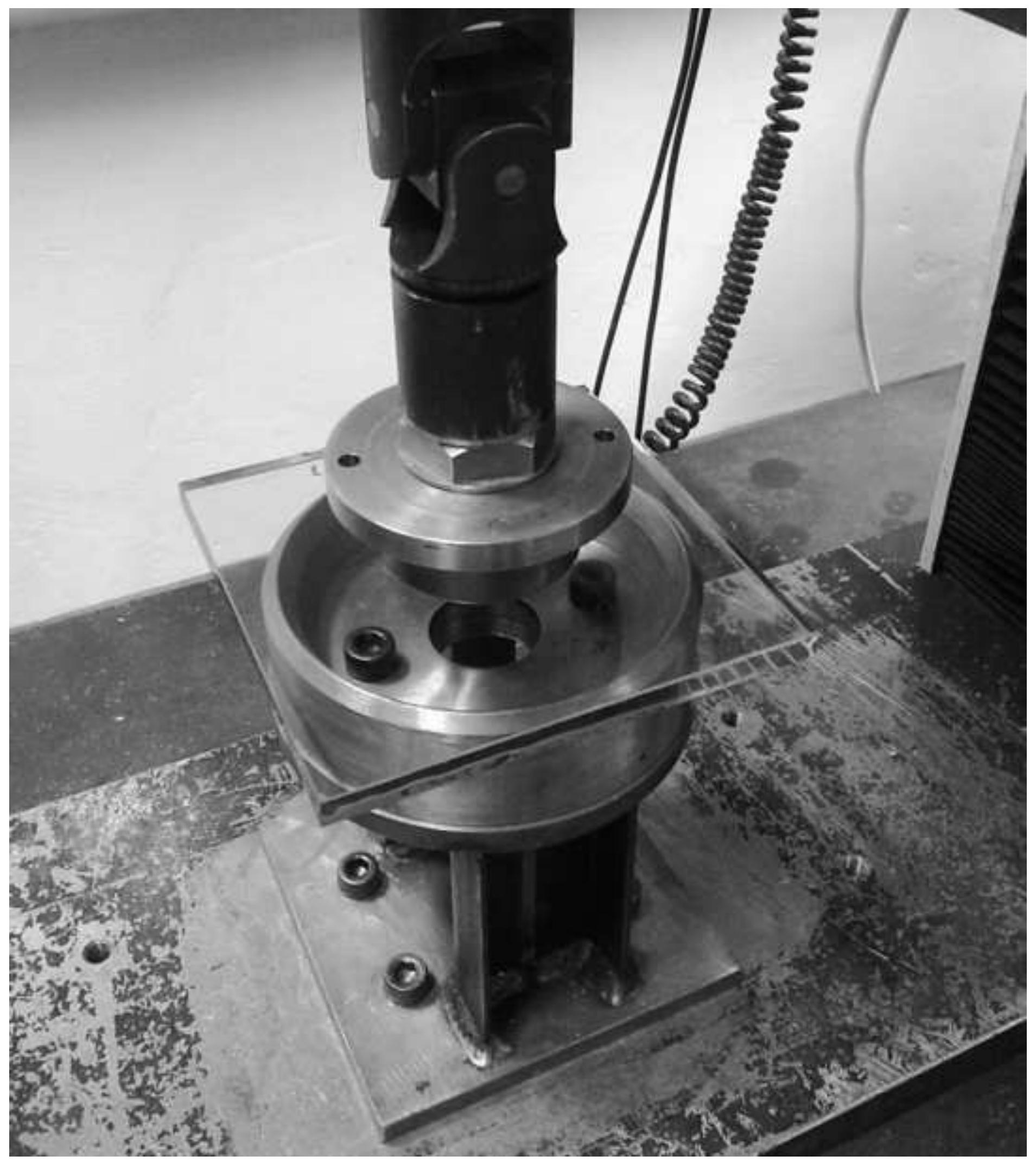




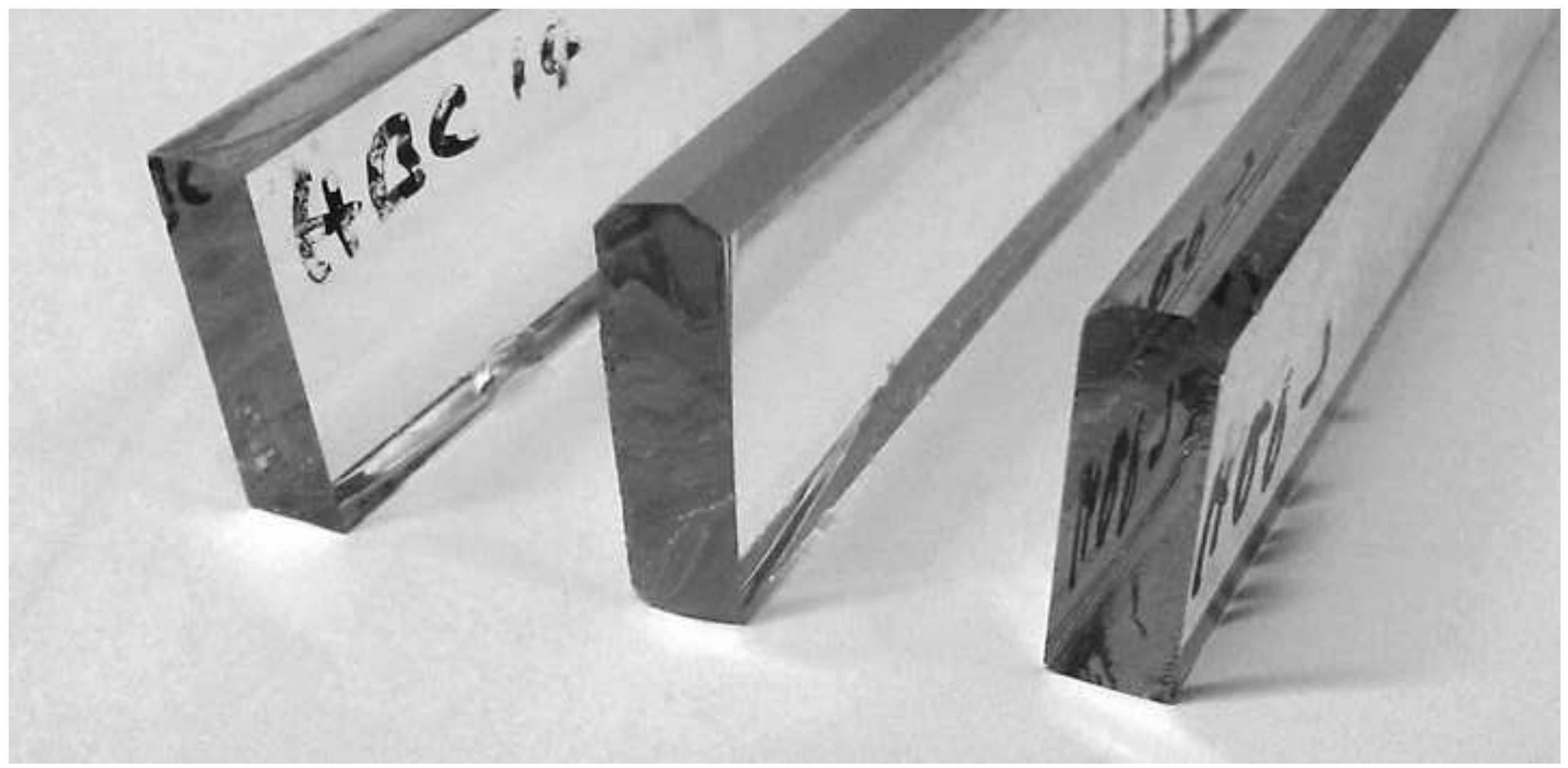



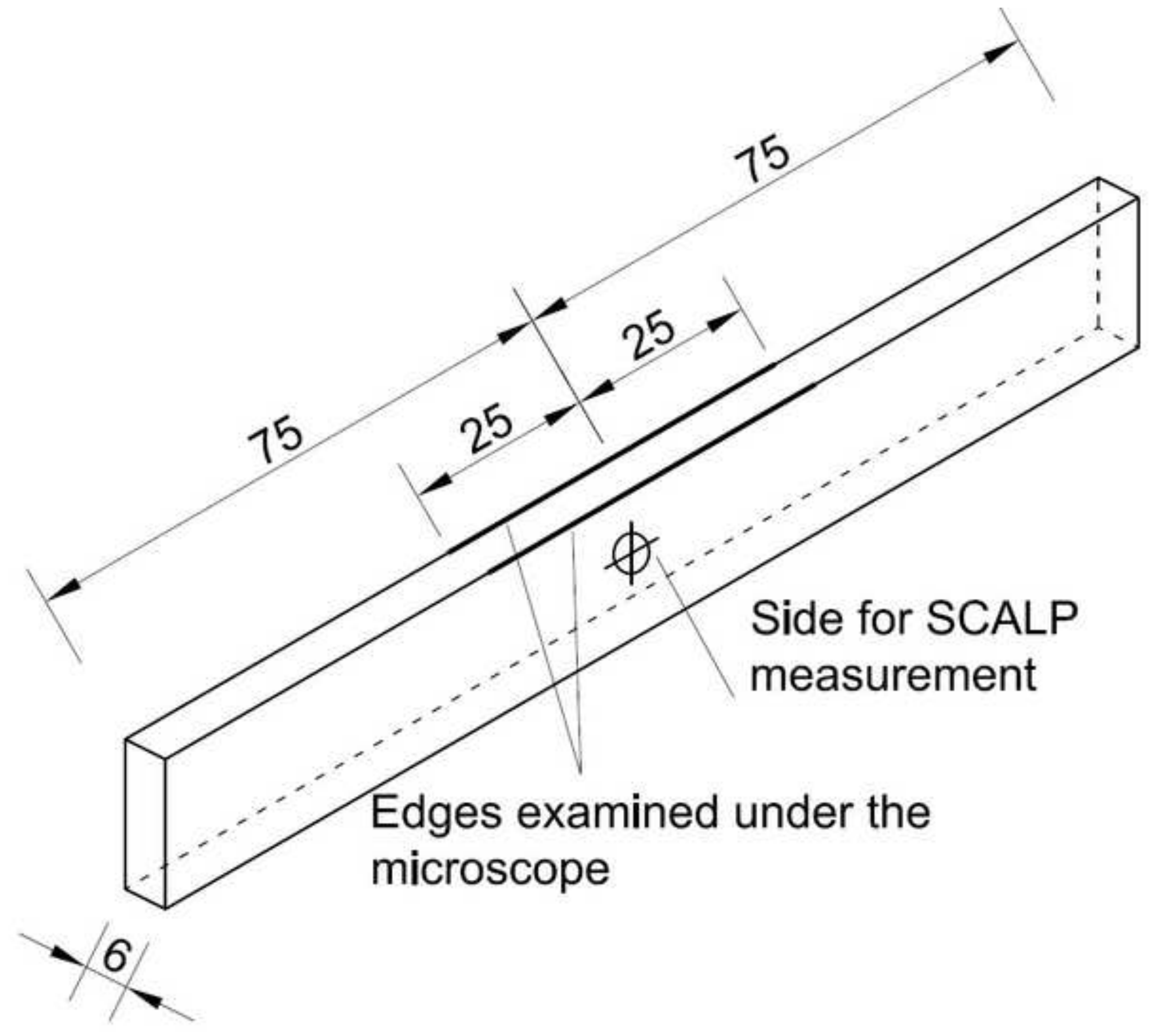


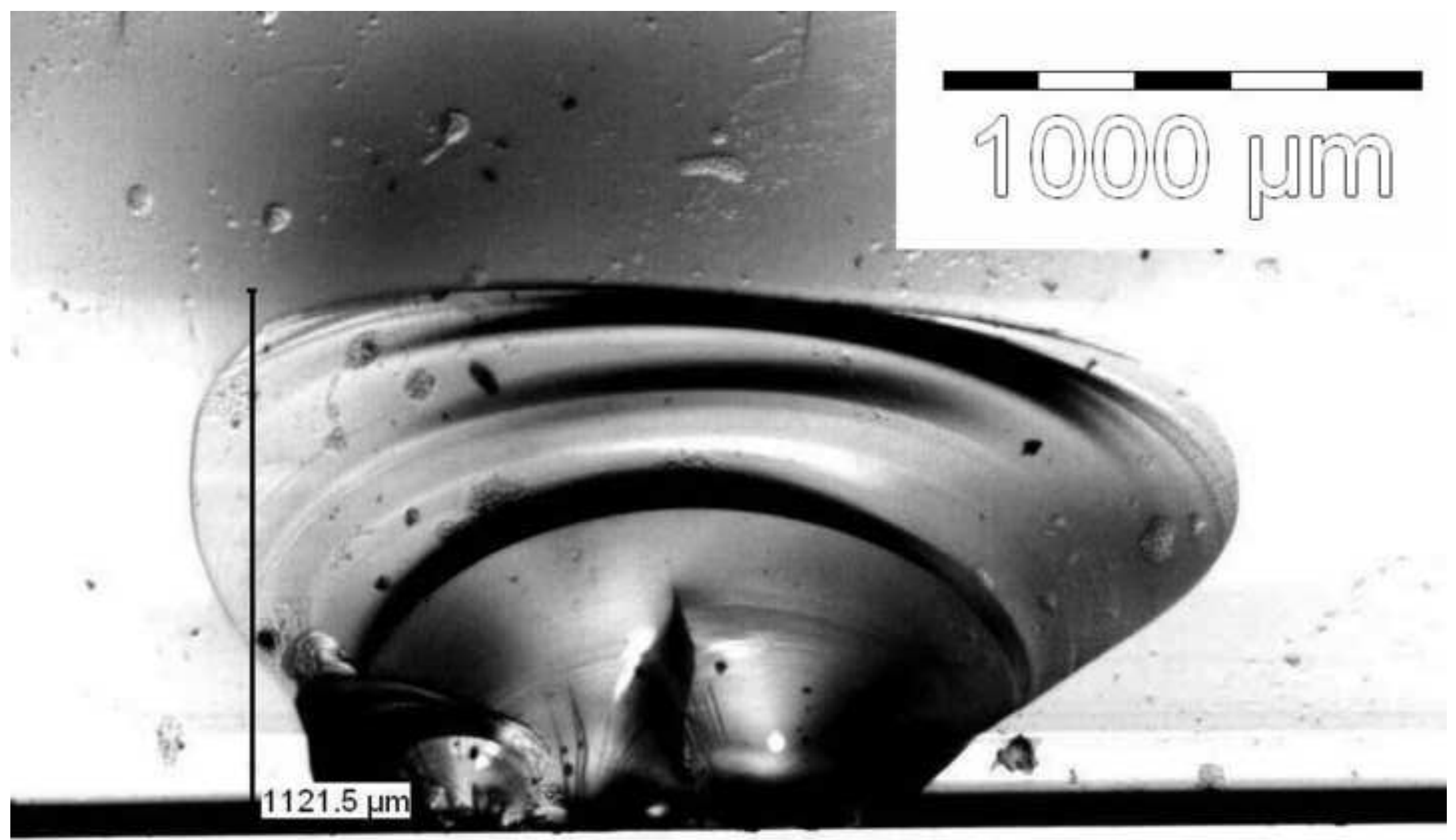




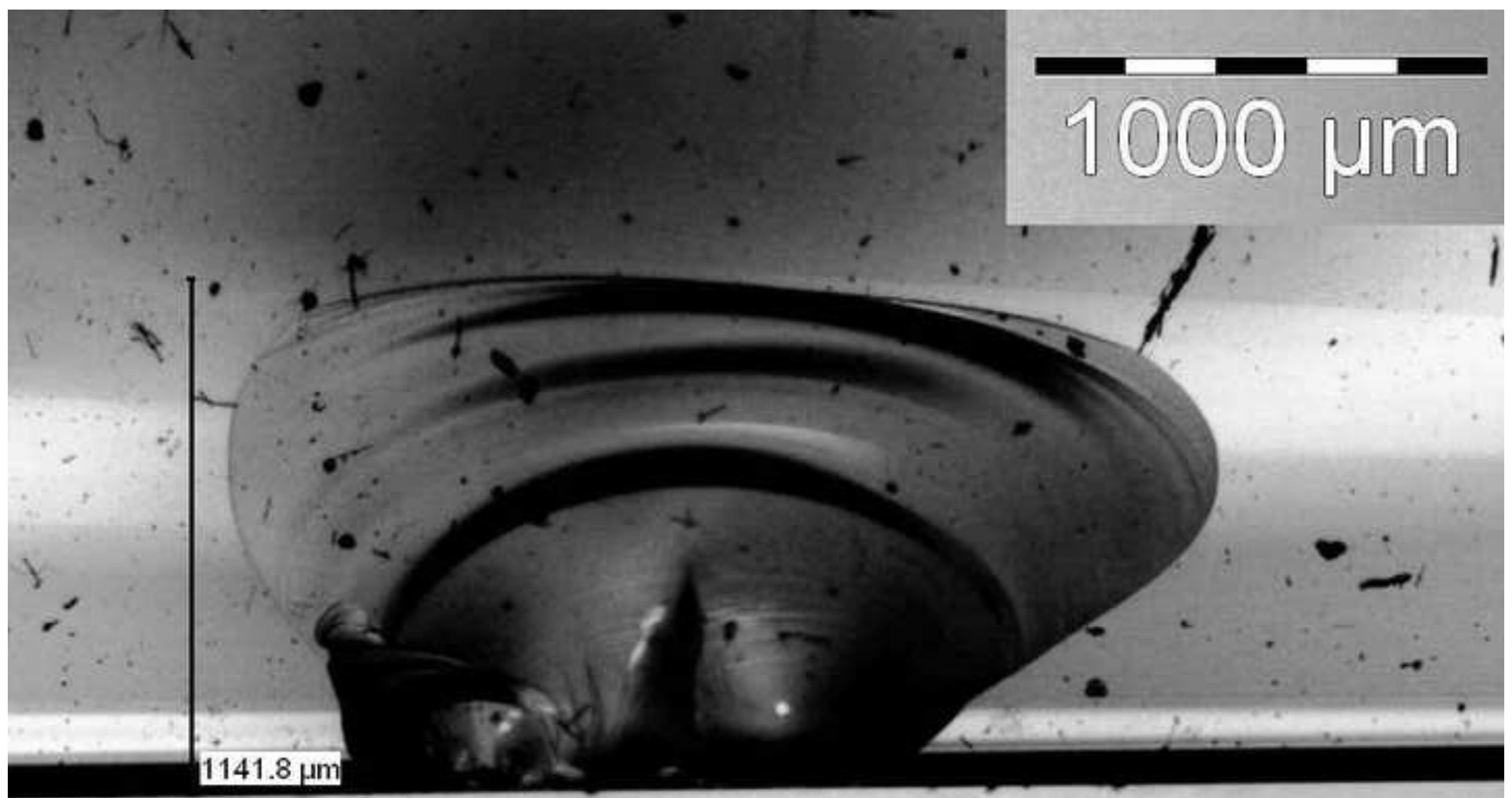




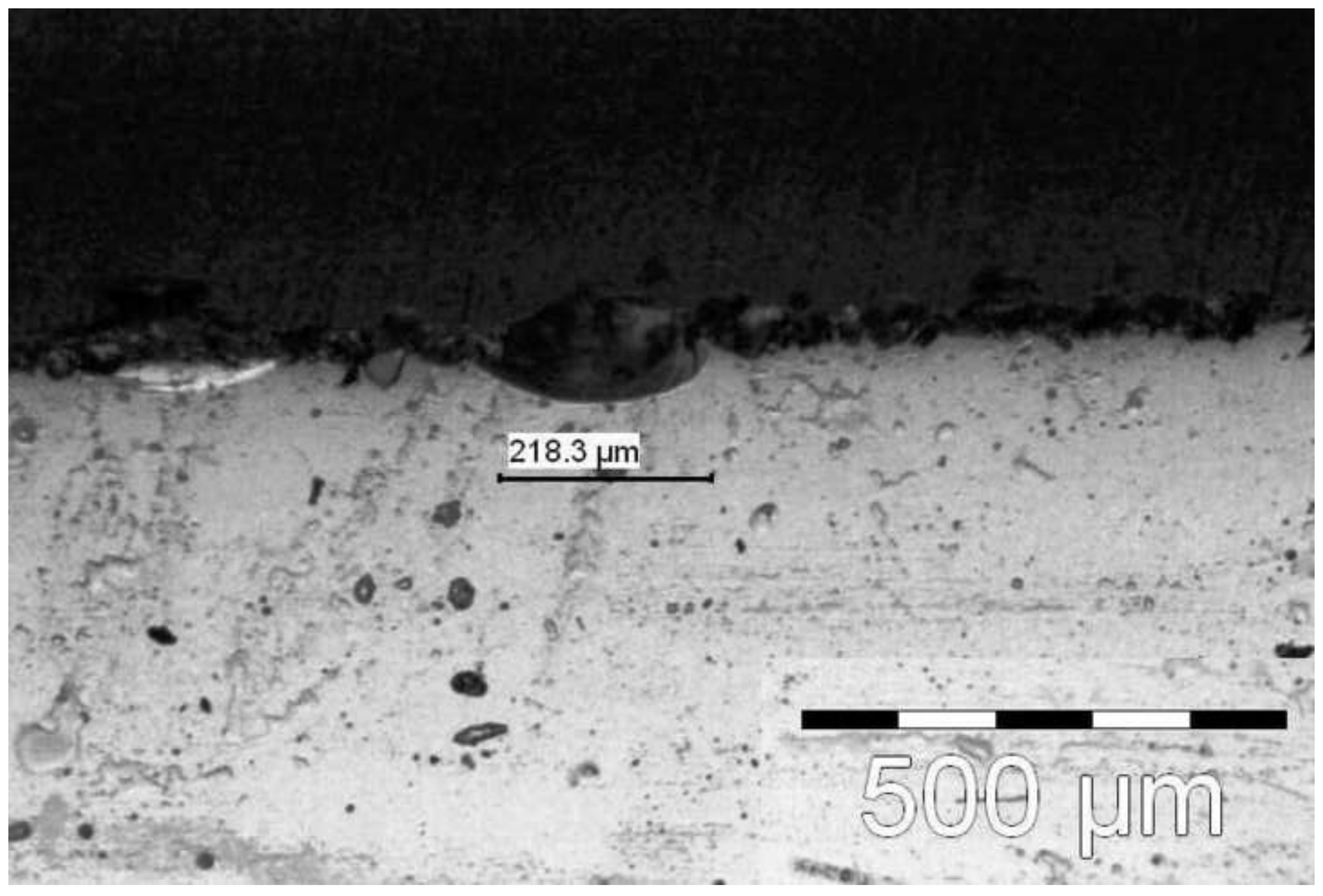




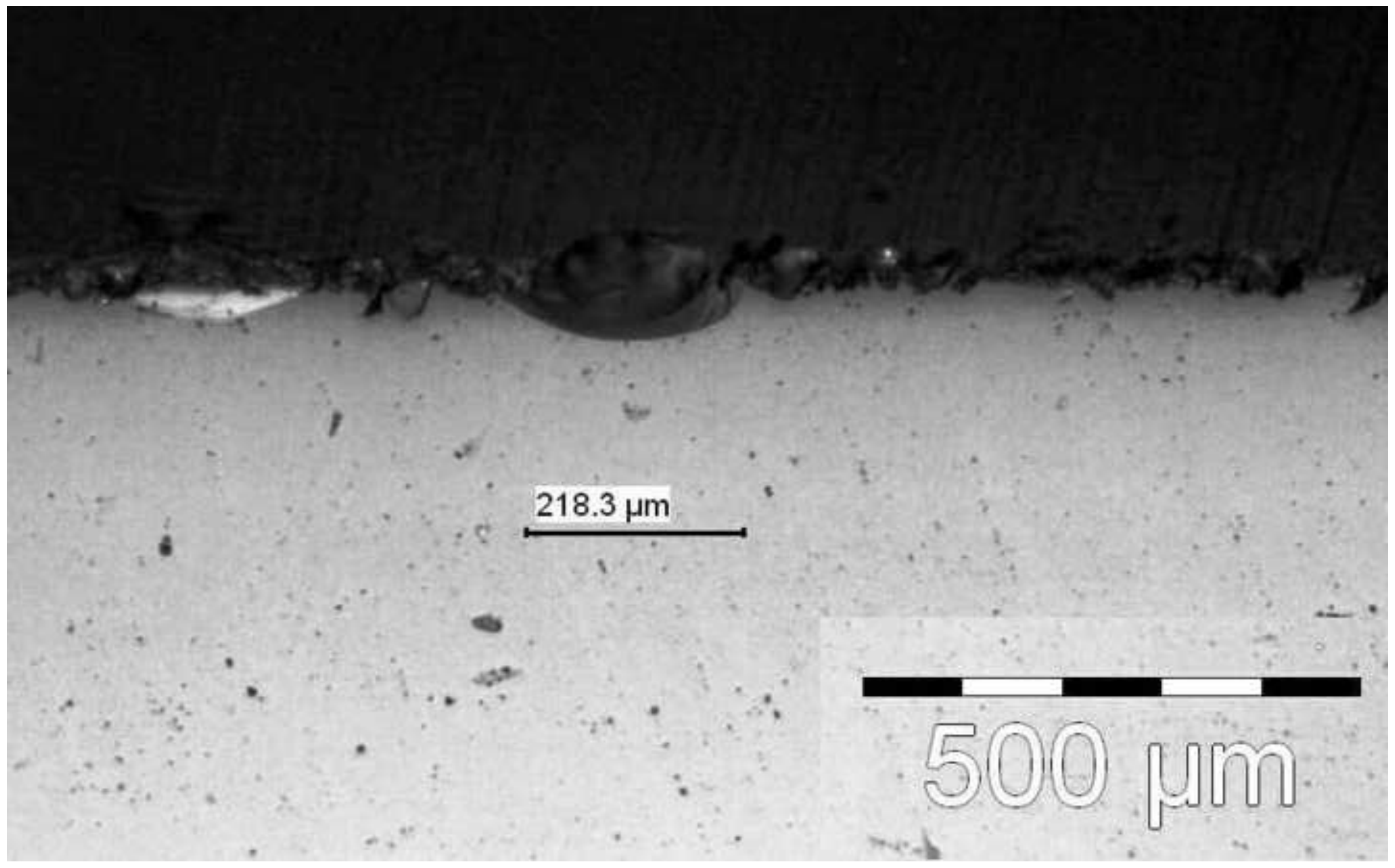




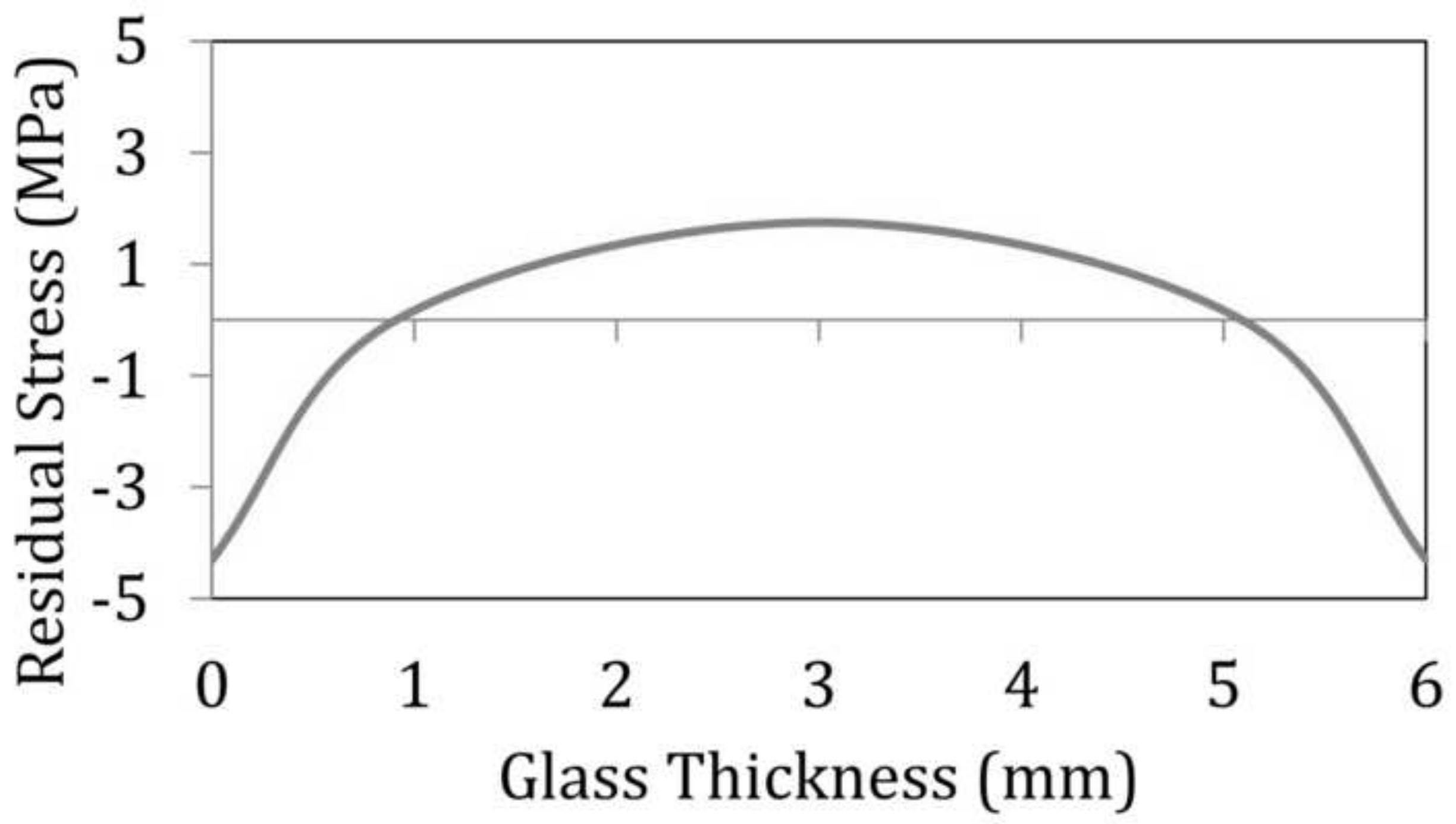




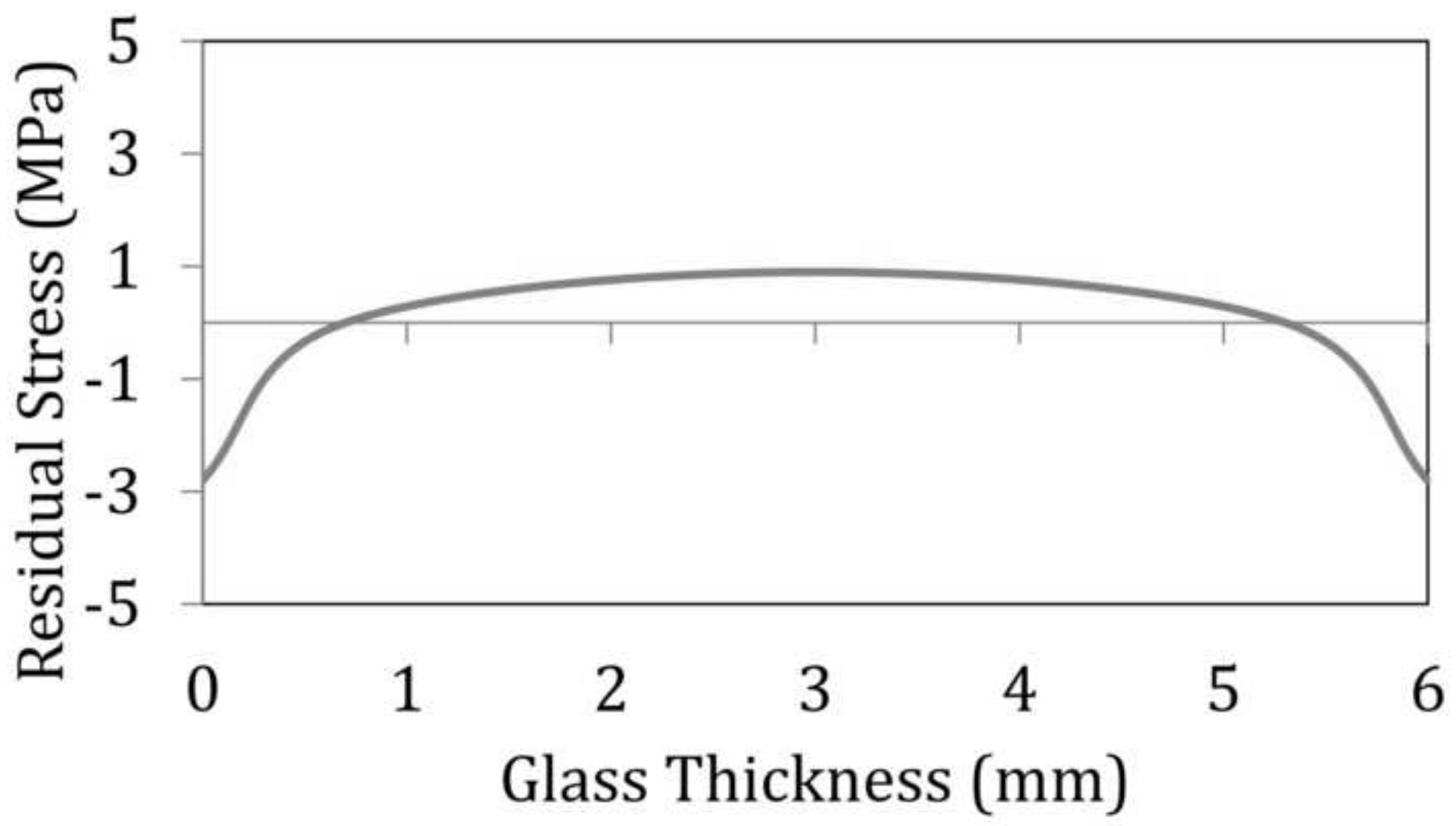




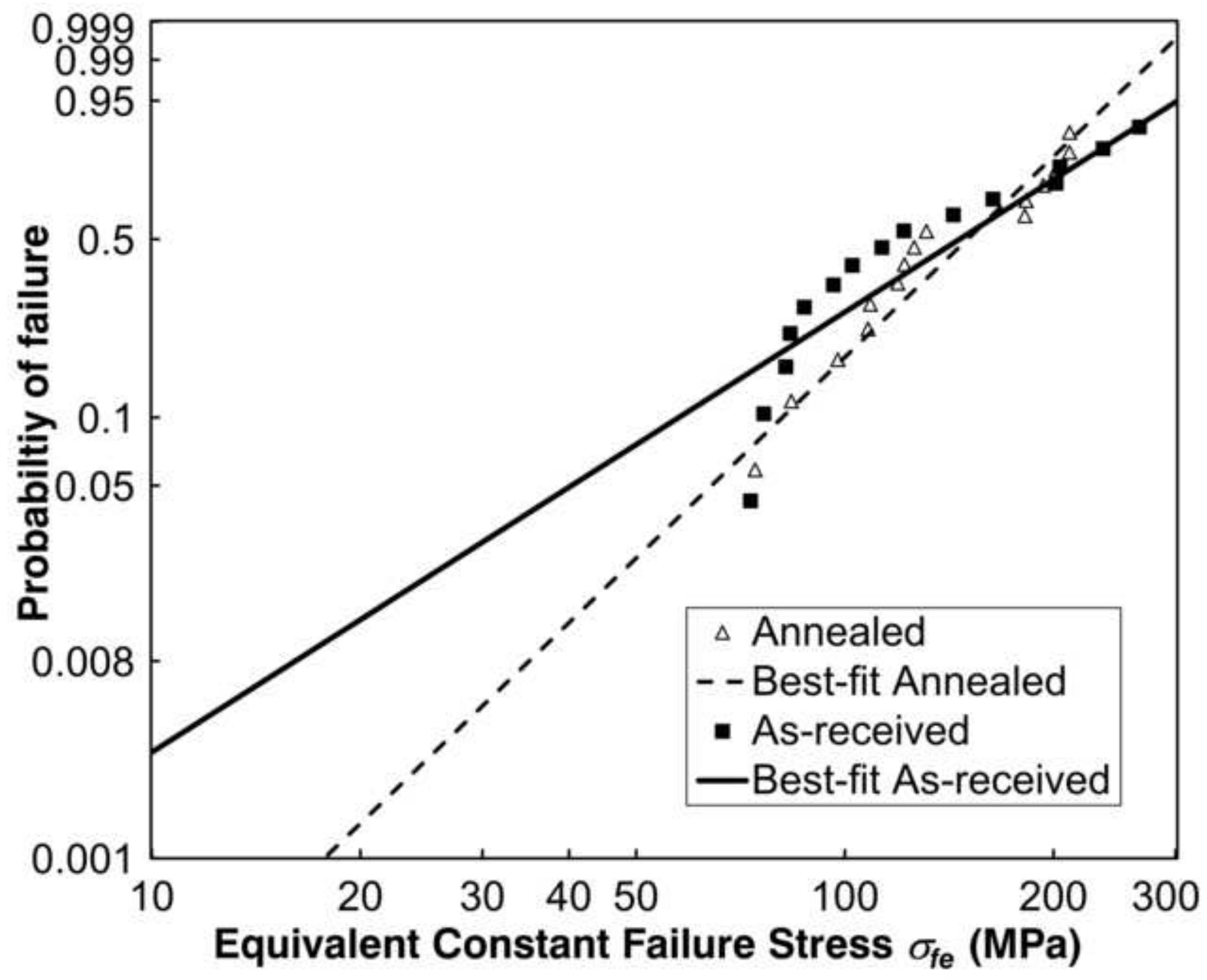




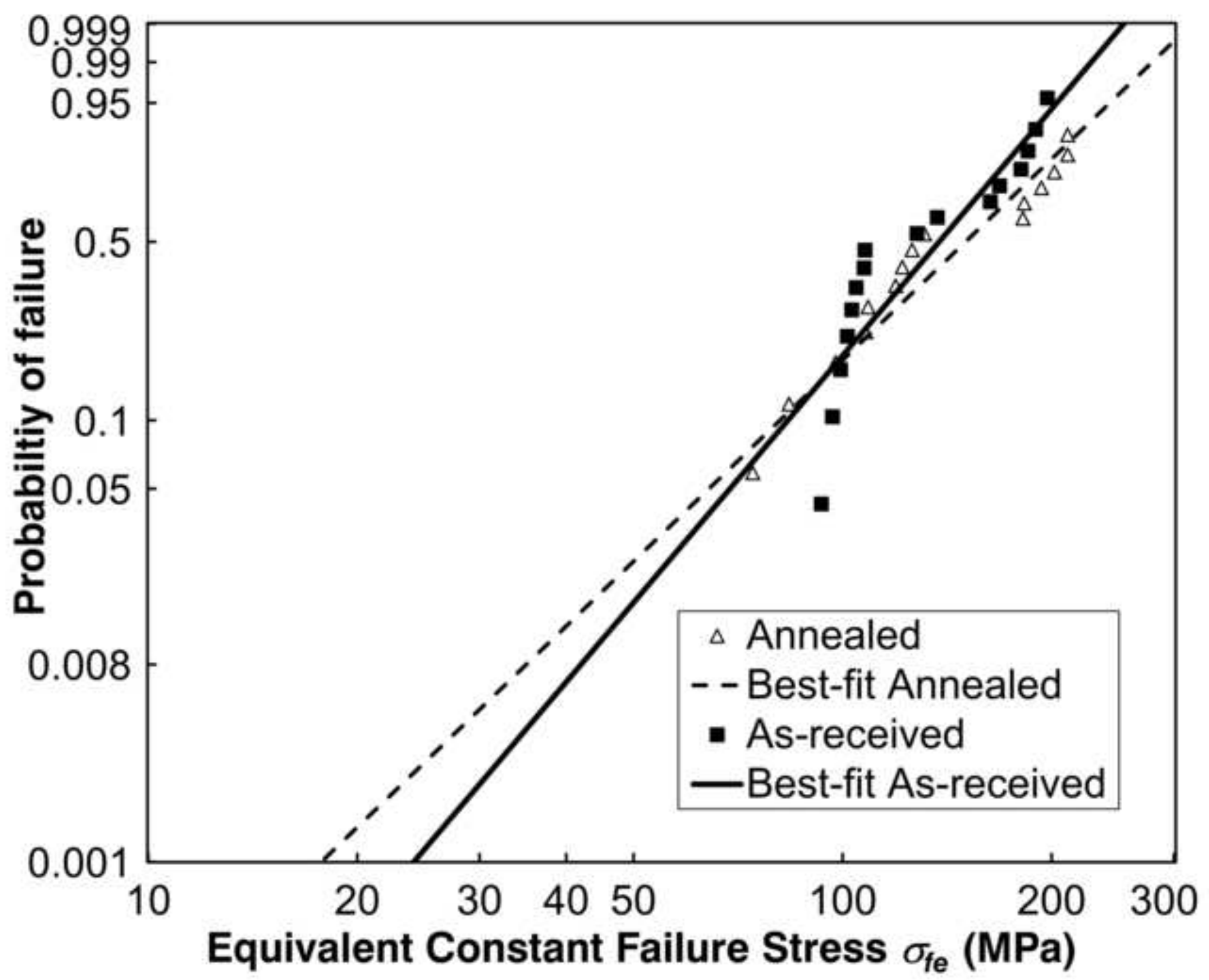




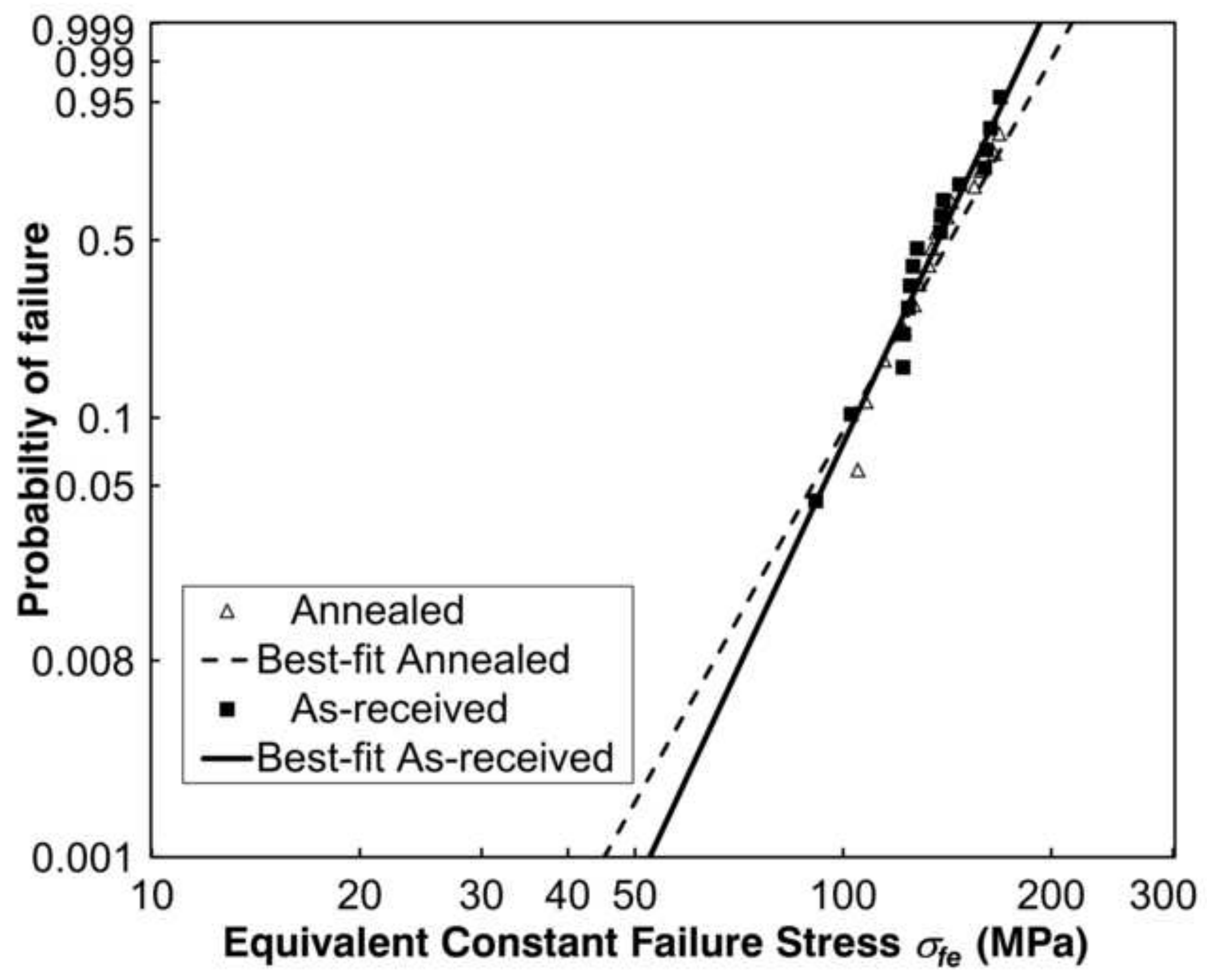




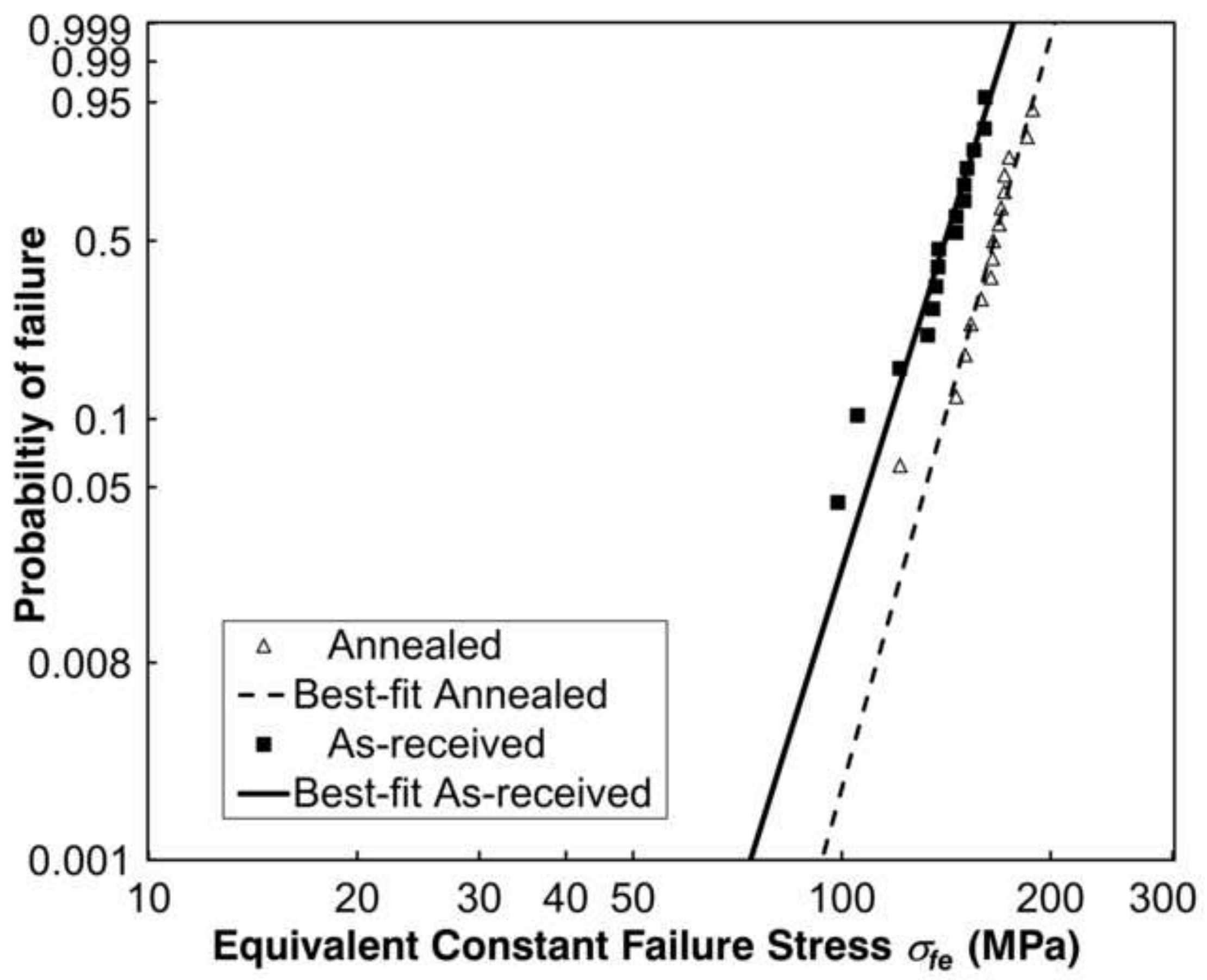




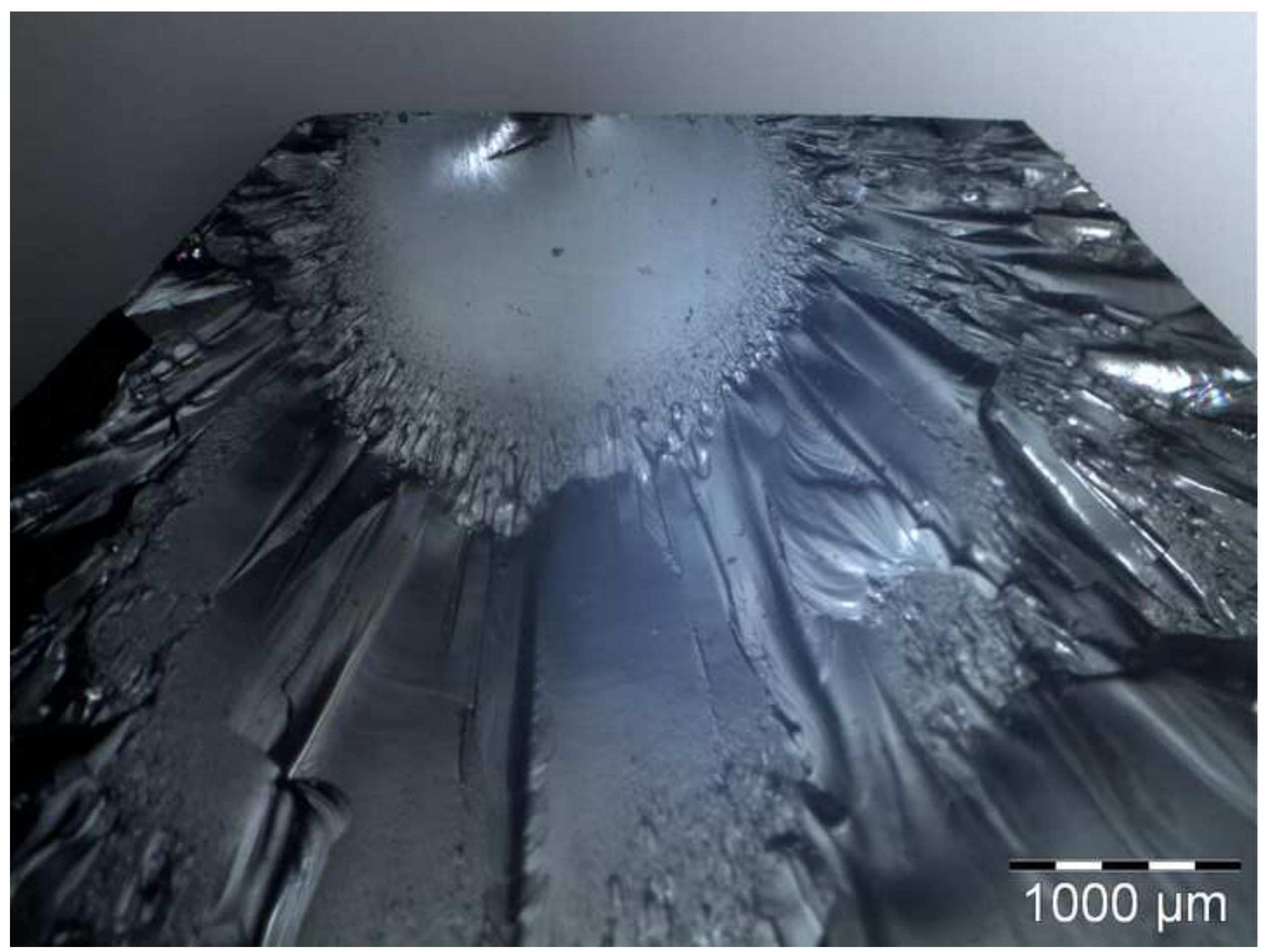




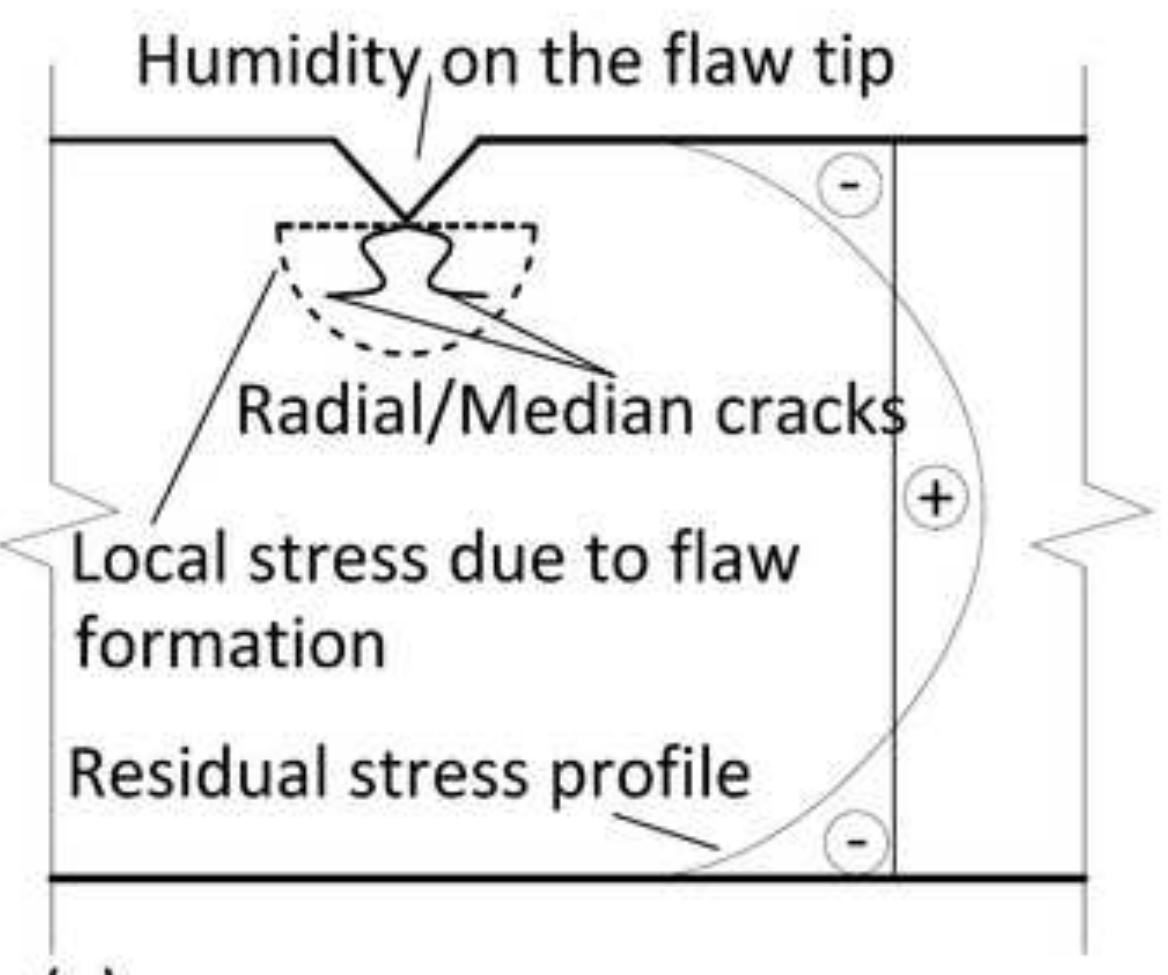

(a)

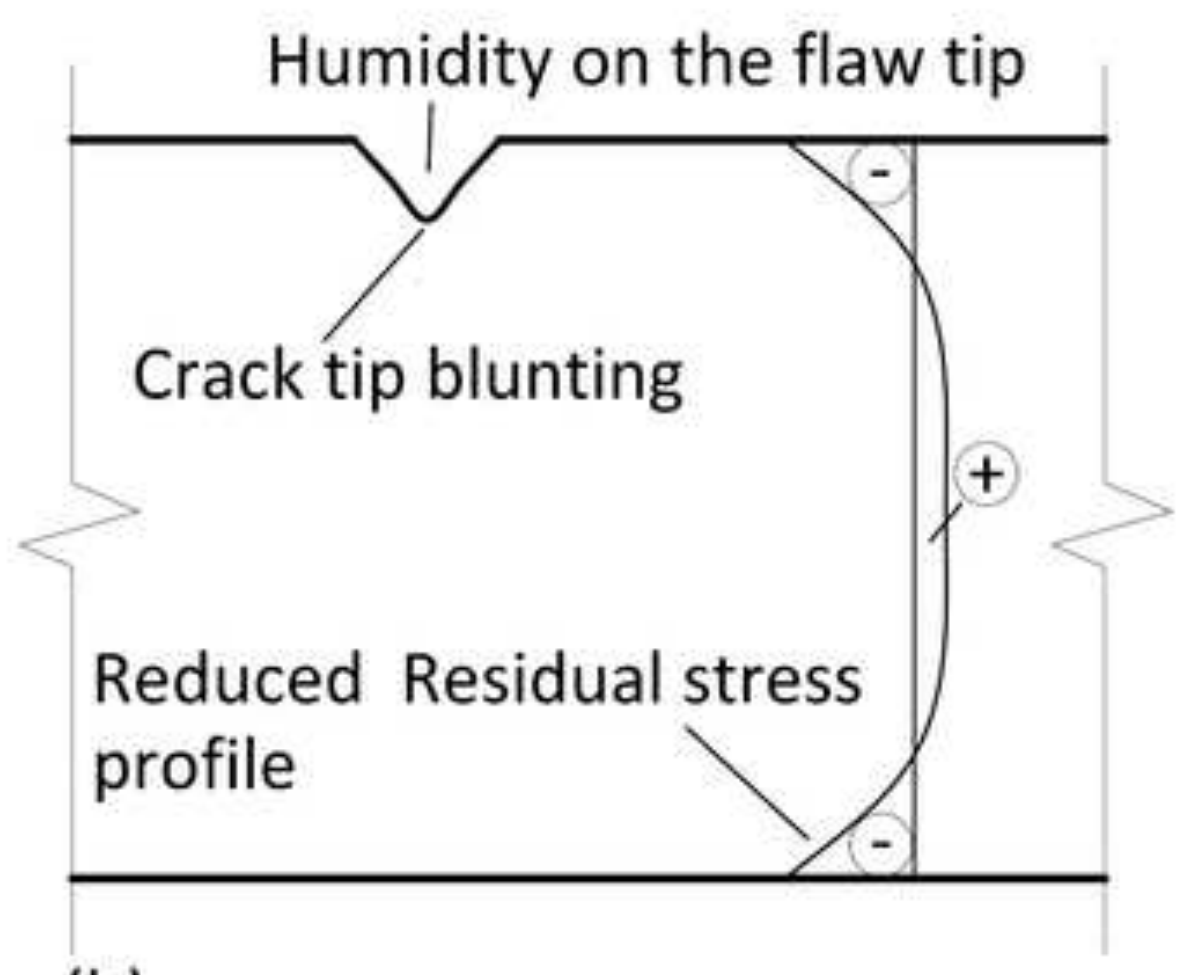

(b) 